\title{
Experimental Investigation and Finite Element (FE) Analysis of the Load- Deformation Response of PVC Fencing Structures
}

\author{
Adeayo Sotayo*ab $^{\text {, Sarah Green }}{ }^{\mathrm{a}}$ and Geoffrey Turvey ${ }^{\mathrm{a}}$ \\ a Engineering Department, Lancaster University, Bailrigg, Lancaster, LA1 4YR. UK \\ ${ }^{b}$ School of Engineering, University of Liverpool, Liverpool, L69 3GH. UK \\ *aba.sotayo@liverpool.ac.uk Phone: +44 (0) 1517957368
}

\section{Abstract}

Polyvinyl Chloride (PVC) posts and rails are increasingly being used as components of fencing structures because of their good mechanical properties, which include long service life, good chemical resistance, ability to be processed into complex geometry and good aesthetics. However, there has been no experimental or Finite Element (FE) study on the load-deformation response of PVC fencing structures. In addition, currently, no stiffness or structural load-bearing design standards exist for these types of fencing structures. Therefore, this study describes an investigation of the loaddeformation response of a two-bay PVC post and rail fencing structure. The fencing structure was loaded experimentally at the top of the centre post and mid-bay points of the top rail. The loaddeflection responses recorded during the tests on the fencing structure are presented and shown to be both linear and repeatable (i.e. three load-unload tests were carried out and showed identical responses). Based on the transverse deflection at the maximum applied load, the transverse stiffness of the two-bay PVC fencing structure was calculated to be $12.7-14 \mathrm{~N} / \mathrm{mm}$. A comparison of the transverse stiffness of the PVC fence with a similar timber fence showed the timber fence was approximately 262 \% stiffer than the PVC fence. Furthermore, FE modelling using a commercial software (ANSYS) was carried out on the PVC fencing structure to supplement the experimental work, and good agreement between the FE analyses and experimental test results was demonstrated. Hence, this paper provides initial knowledge and understanding of the linear elastic load-transverse deflection response of PVC fencing structures, and constitutes useful structural design guidance for what may be regarded as the in-service or practical deformation limit. The results of this study also provide useful benchmarks for future composite materials and components for fencing and other structural applications.

\section{Keywords}

Experimental testing; Finite element analysis; PVC post and rails; PVC fencing; Structures 


\section{Introduction}

PVC is a highly versatile thermoplastic material that is used in built environment applications that include fencing, flooring, pipes and fittings, cables and window profiles. In 2014, about 0.2 (UK) and 1.3 (Europe) million tonnes of PVC were used in the production of rigid PVC profiles (European Council of Vinyl Manufacturers 2014, PlasticsEurope 2015). For such applications, PVC offers good mechanical properties, can be formed into complex shapes/geometry, has resistance to chemical attack and water ingress, and has a long service life (Agarwal and Gupta 2011, Yu et al. 2016). Fillers, lubricants, pigments and other additions are made to PVC to improve processing (i.e. melt flow) and influence properties such as colour, stiffness, strength, flammability and chemical resistance (Kalpakjian 1984, Patrick 2005), with such additions typically constituting $10-20 \%$ by weight (American Chemistry Council 2008).

PVC extrusions, in the form of posts and rails, are increasingly finding application as alternatives to timber components in agricultural fencing applications. Although PVC fencing usually has higher initial costs than timber alternatives, through-life maintenance costs are typically lower because PVC does not require periodic painting and preservation treatments to protect against environmental decay (i.e. water ingress and fungal attack). PVC fence components can also exhibit superior dimensional stability under seasonal variations in temperature and humidity, and also better resistance to ultraviolet degradation (German 1992). However, because PVC has a lower flexural modulus than timber, PVC fencing structures often require steel reinforcement to increase their overall stiffness and strength.

Figure 1 shows a PVC post and rail fencing system (an equine enclosure) installed in a typical agricultural setting where in normal service, a variety of loadings (i.e. bending, torsion, shear, impact) must be withstood. ASTM F964 (2013) provides the specification for rigid PVC profiles used in agricultural, residential and commercial fencing and ASTM F1999 (2006) provides the installation specification for rigid PVC post and rail fencing. However, the structural loadbearing requirements of the PVC structural members and/or the fence assembly are not addressed in these standards. Equally, there is no current stiffness or structural load-bearing design standard or in-service compliance guidance available for PVC fencing or even agricultural fencing in general. 


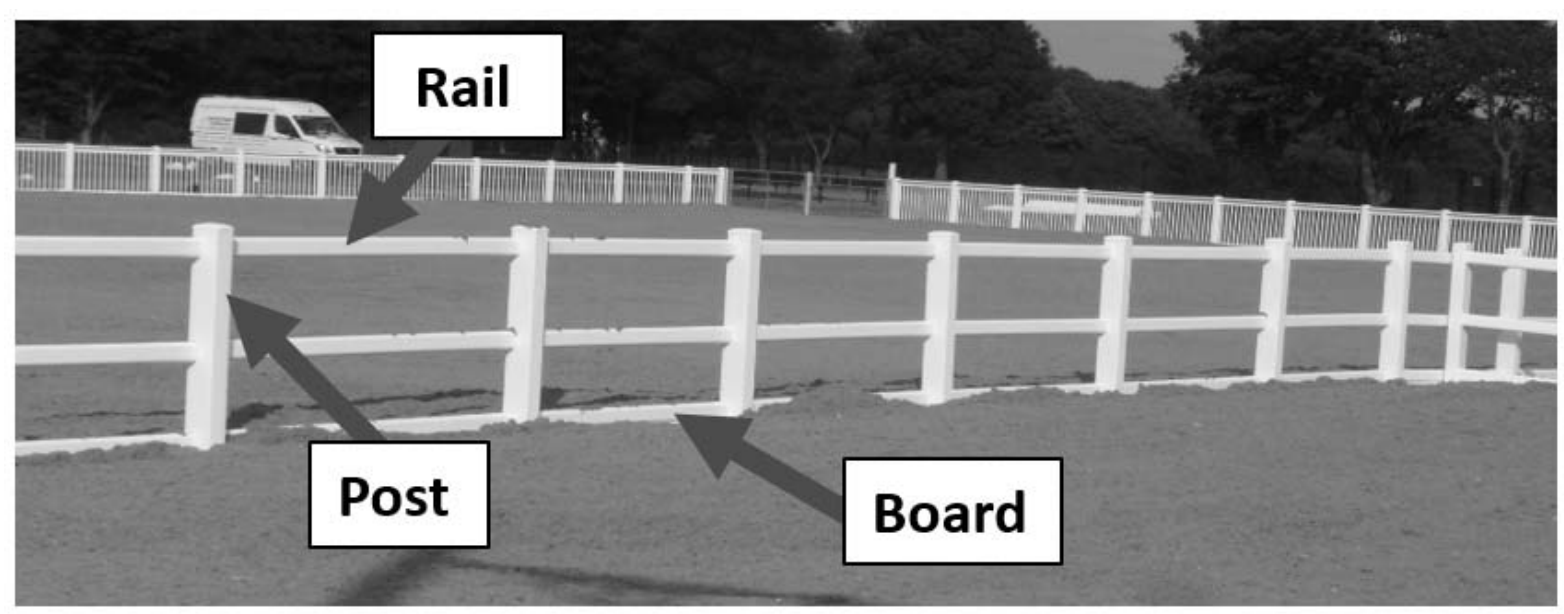

Figure 1: Typical agricultural PVC post and rail fencing system

Recently, the authors undertook an investigation of the load-deformation response of an agricultural timber fencing structure (Sotayo, Green, and Turvey 2016). The structure comprised of three posts and two rails, and was tested under incremental static loading applied normal to the plane of the structure at the mid-point of the top rail. The experimental load versus deformation response was also simulated using FE analysis software (ANSYS Workbench Release 15), and good agreement between the FE model and the physical behaviour was demonstrated. Similar loading tests on pultruded GFRP composite guard-rails have been undertaken (Turvey 2015) and their load-deformation and transverse stiffness characteristics were quantified.

The primary objective of this study is to add to the limited knowledge base on the serviceability deformation response of PVC post and rail fencing structures. This is because, based on the Authors' extensive knowledge of the literature, there have been no load tests or FE analyses reported on PVC fencing in the open literature. Therefore, for the first time, important experimental work was carried out to investigate and characterise the load deformation response of PVC fencing, and FE modelling with ANSYS was also carried out to predict the load-deformation response of PVC fencing for reasonably large transverse deflections. This work also seeks to inform material selection and design of fencing structures through improved understanding of the load-deformation response of PVC fencing, which may be transformed into useful structural design guidance. It is also worth noting that there has been an upsurge in the development of novel structural materials in recent years, and the relatively low flexural stiffness of some of these materials (compared to steel) has led to their use in secondary load-bearing structures, e.g. fencing applications. This study evaluates and 
quantifies the transverse stiffness of a representative PVC fence, and therefore acts as a benchmark which may be useful for evaluating the structural design and analysis (i.e. changes to cross-sections of the structural members, overall geometry/layout etc.) of future novel materials and components for fencing applications.

The structure of the paper takes the following form. First, the geometry and material properties of the PVC posts and rails are presented. This is followed by a description of the joint at the base of each post, the overall geometry and the loading procedure adopted for the experimental load tests on the two-bay PVC fence. The test setup is representative of a typical multi-bay fencing system, and is similar to that described in Turvey (2015) and also Sotayo et al. (2016). Guard-rail and safety barrier structures, which share similarities with the fencing structures investigated in the present work, are service-load tested by the application of loads at the top of the centre post and mid-bay points of the top rail of a two-bay frame (BS 14122-3 2016). Hence, it was deemed reasonable to apply the loads at the top of the centre post and the mid-bay points of the top rail of the PVC fencing structure. The graphs of the experimentally derived load-deformation responses of the PVC fence are then presented and discussed. In addition, the transverse stiffness of the two-bay PVC fence was determined and compared with the transverse stiffness obtained from similar tests on the timber fence reported in Sotayo et al. (2016). The findings of FE simulations of the physical tests are reported in order to quantify how well the load-deformation response of the fence was modelled, and are essential information if costly and time-consuming physical tests are to be avoided. Comparisons between the modelled and experimental deflections are presented. Finally, the main conclusions of the investigation are summarised.

\section{Properties of the PVC posts and rails}

Extruded hollow PVC posts and rails were supplied by Equestrian Surfaces, Lancashire, UK and are typical of those used for agricultural fencing. A material specification sheet listing the mechanical properties of the rigid PVC was provided by the manufacturer, Duralock Performance Fencing (2014); the flexural modulus ranged from $2.373 \mathrm{GPa}$ to $2.510 \mathrm{GPa}$, and the tensile strength from $45 \mathrm{MPa}$ to $50 \mathrm{MPa}$. Sketches of the cross-sections of the PVC posts and rails are shown in Figure 2 and Figure 3, respectively and Figure 4 shows details of the rail cut-outs in the posts. Five tension coupon tests were carried out on rectangular coupons cut 
longitudinally out of the PVC posts to determine their elastic moduli and strengths (BS 527-1 2012). These tensile tests were carried out at an extension rate of $2 \mathrm{~mm} / \mathrm{min}$ using a universal testing machine (Zwick Z020) which had a load capacity of $20 \mathrm{kN}$. The PVC coupons had dimensions of $20 \mathrm{~mm}$ (width) $\times 3 \mathrm{~mm}$ (thickness) $\times 180 \mathrm{~mm}$ (length). The longitudinal extensions of the PVC coupons were recorded using a mechanical extensometer, with a 50 mm gauge length.

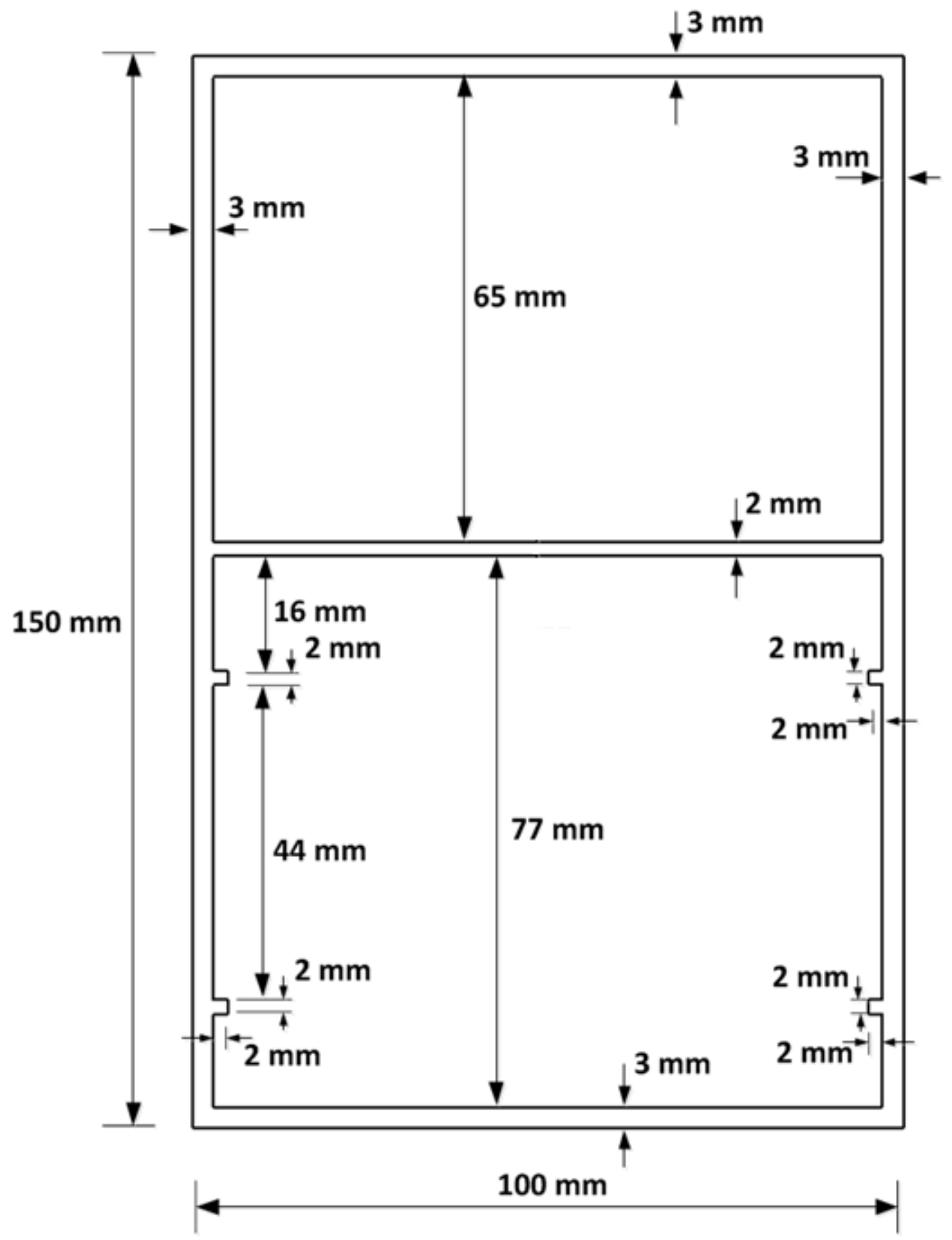

Figure 2: Cross-section of a PVC post 
Three-point bending tests were also carried out on three PVC posts and three PVC rails to determine their elastic flexural moduli (BS EN 178 2013). Details of their geometry are given in Figure 2 - Figure 4. The PVC posts and rails were simply supported on steel rollers and loaded by means of dead weights added to a hanger located at mid-span. The centre deflection corresponding to each increment of load was recorded by a dial gauge with a 50 $\mathrm{mm}$ travel and a displacement resolution of $0.01 \mathrm{~mm}$. Average values and standard deviations of the experimental tensile strength, elastic tensile and flexural moduli, together with the manufacturer's values are given in Table 1. It is evident that the experimental flexural modulus is at least $8 \%$ greater than the manufacturer's value. Also, the experimental tensile strength lies within the manufacturer's range of values.

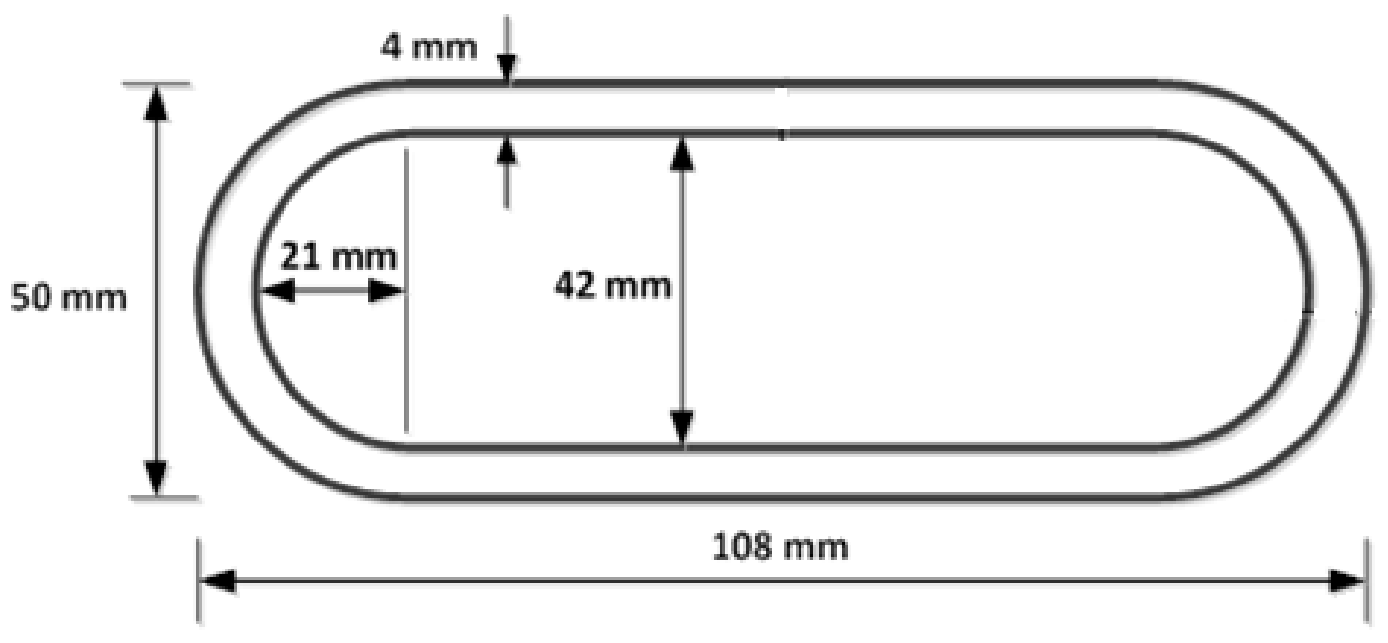

Figure 3: Cross-section of a PVC rail

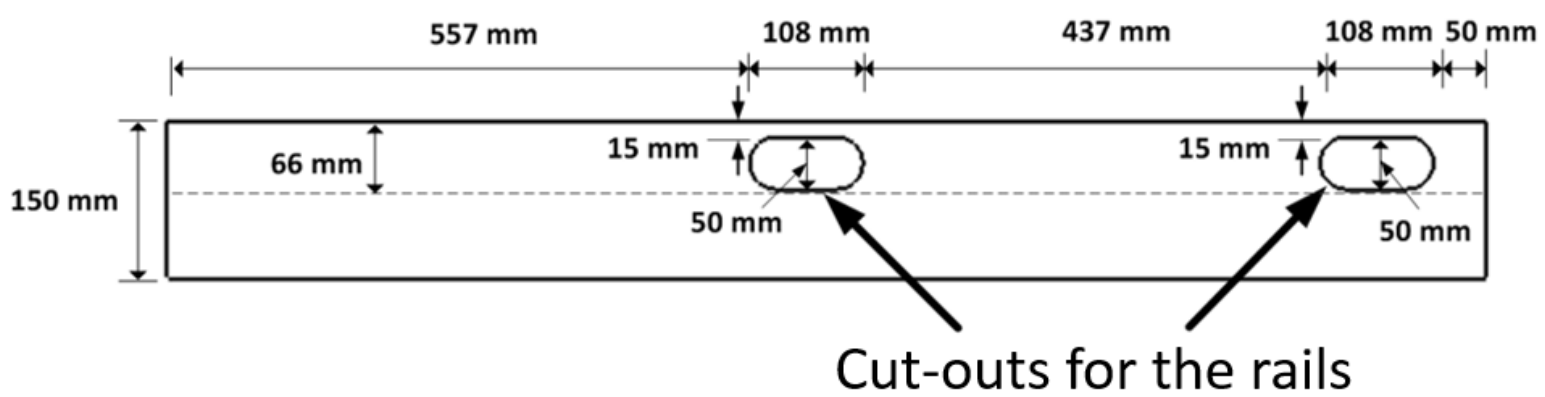

Figure 4: Side-view of a PVC post 
Table 1: Elastic moduli and strength of the PVC material

\begin{tabular}{|c|c|c|c|}
\hline $\begin{array}{c}\text { Manufacturer's values } \\
\text { (Duralock Performance Fencing 2014) }\end{array}$ & $\begin{array}{c}\text { Elastic tensile } \\
\text { modulus } \\
{[\text { GPa] }}\end{array}$ & $\begin{array}{c}\text { Elastic flexural } \\
\text { modulus } \\
{[\text { GPa] }}\end{array}$ & $\begin{array}{c}\text { Tensile } \\
\text { strength } \\
{[\mathrm{MPa}]}\end{array}$ \\
\hline Experimental values & $3.4 \pm 0.2$ & $2.4-2.5$ & $45-50$ \\
\hline \multicolumn{2}{|c|}{$2.7 \pm 0.1$} & $45 \pm 1.5$ \\
\hline
\end{tabular}

\section{Experimental Test Setup}

Load tests were carried out on a two-bay PVC post and rail fence that comprised of three posts and two rails, as shown in Figure 5 . In this design of fence, the rails locate via a sliding fit through cut-outs in the posts.

The details of the base connections for the posts are shown in Figure 6 and Figure 7. In service, each PVC post locates on a steel base plate assembly (with welded steel angles), which normally extends into a cemented foundation mass. To represent the post base-to-ground connection in the laboratory, steel base plate assemblies were manufactured and bolted to the laboratory strong floor. The geometry of the steel base plate assembly used is shown in Figure 6, and this was bolted to the laboratory floor using $46 \mathrm{~mm}$ diameter steel fixings torqued to $30 \mathrm{Nm}$. The posts were located over the welded steel angles so that their faces contacted the interior faces of the post, and the base of the post was in contact with the top surface of the $4.5 \mathrm{~mm}$ thick steel plate (see Figure 7).

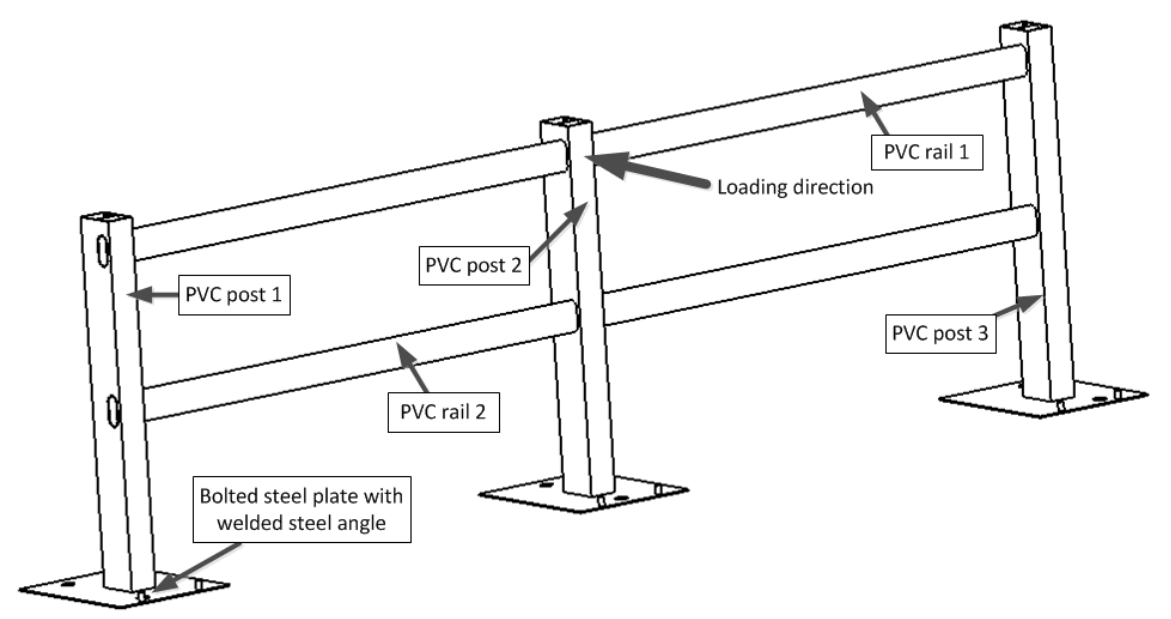

Figure 5: Diagram of the test setup for the two-bay PVC post and rail fence 


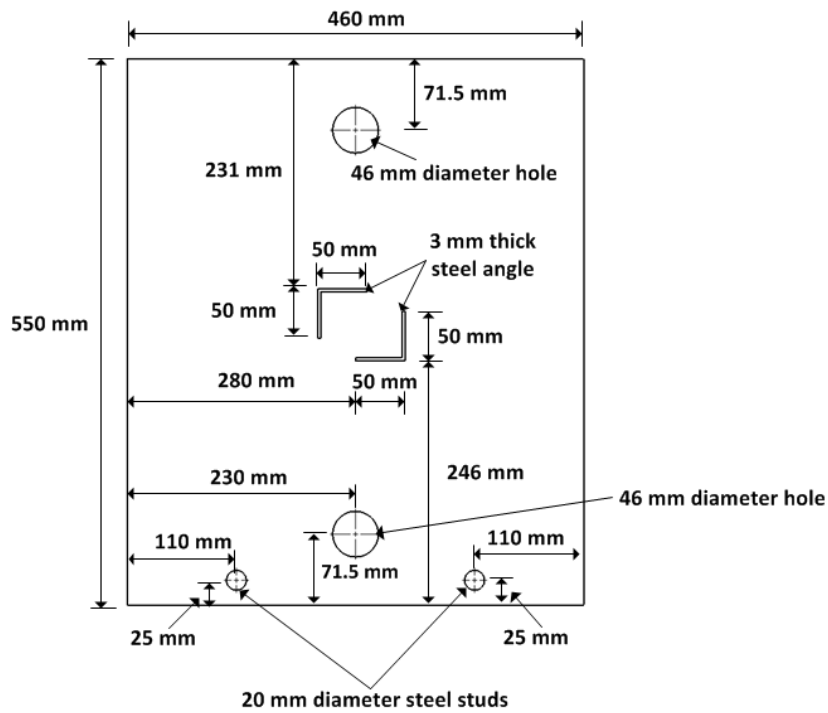

(a)

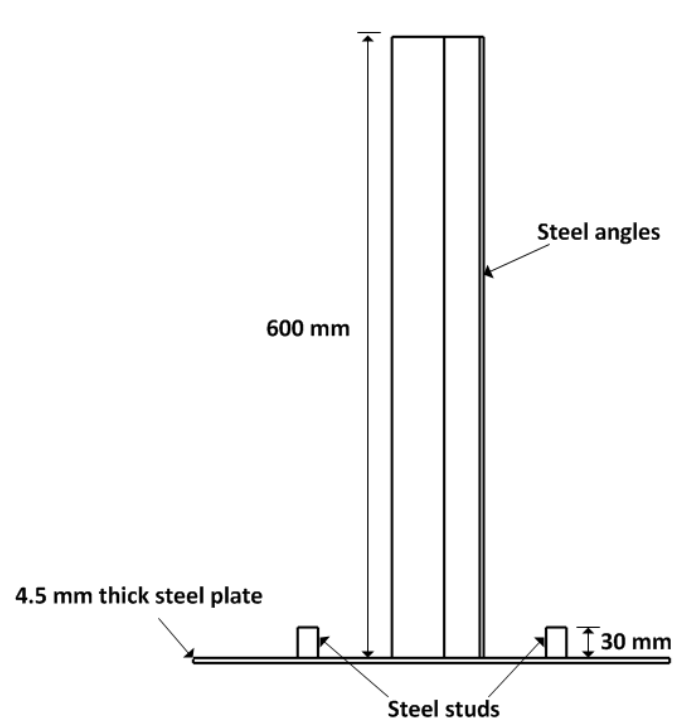

(b)

Figure 6: Details of the steel base plate with welded steel angles and circular steel studs:

(a) Plan view and (b) Front view

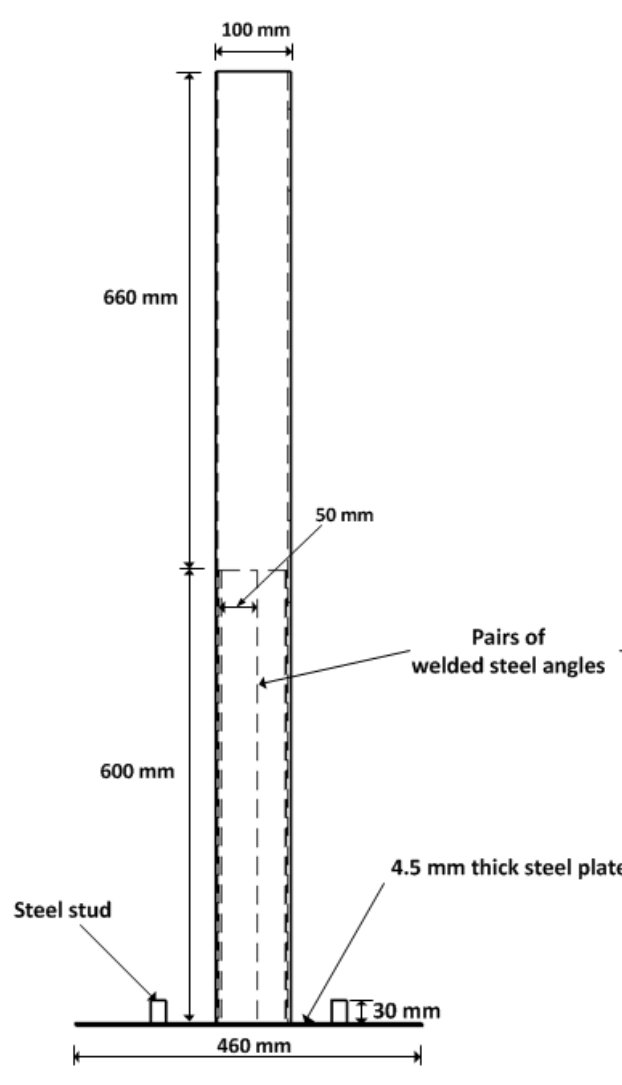

(a)

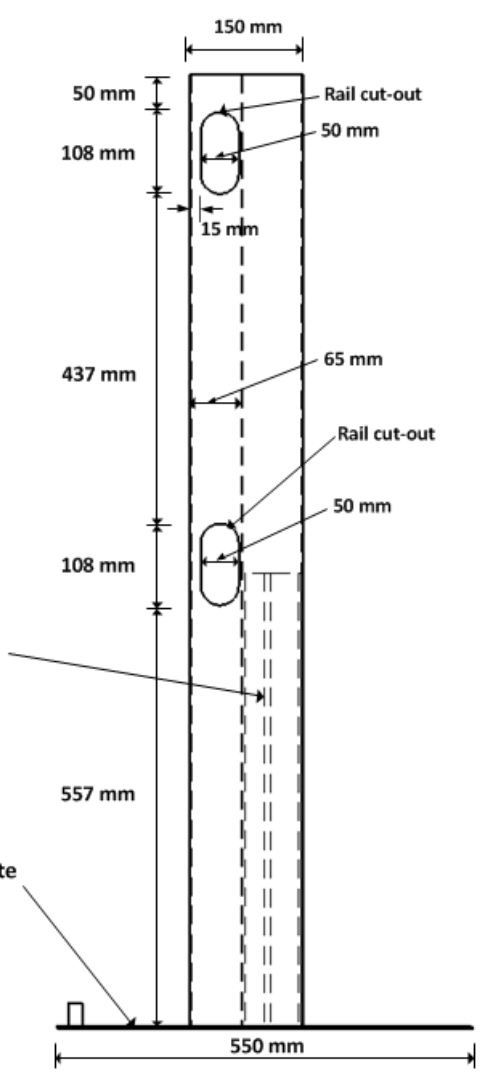

(b)

Figure 7: PVC post located on the base plate: (a) Front view and (b) Side view 


\section{Load-Deflection Tests on the Two-Bay PVC Fences}

Two PVC post and rail fences were tested. The overall geometries of the two fences are shown in Figure 8 and Figure 9. The overall geometry of the first fence is typical of that used for agricultural PVC fencing. However, in the second fence, the spacing between the PVC posts was reduced from $2000 \mathrm{~mm}$ to $1800 \mathrm{~mm}$ to match that of the timber fence tested by Sotayo et al. (2016). Hence, the load-deflection results from the test on the second PVC fence can be compared with the test results of the timber fence given in Sotayo et al. (2016). It is, however, worth highlighting that the heights of the timber $(1300 \mathrm{~mm})$ and PVC $(1260 \mathrm{~mm})$ posts were marginally different.

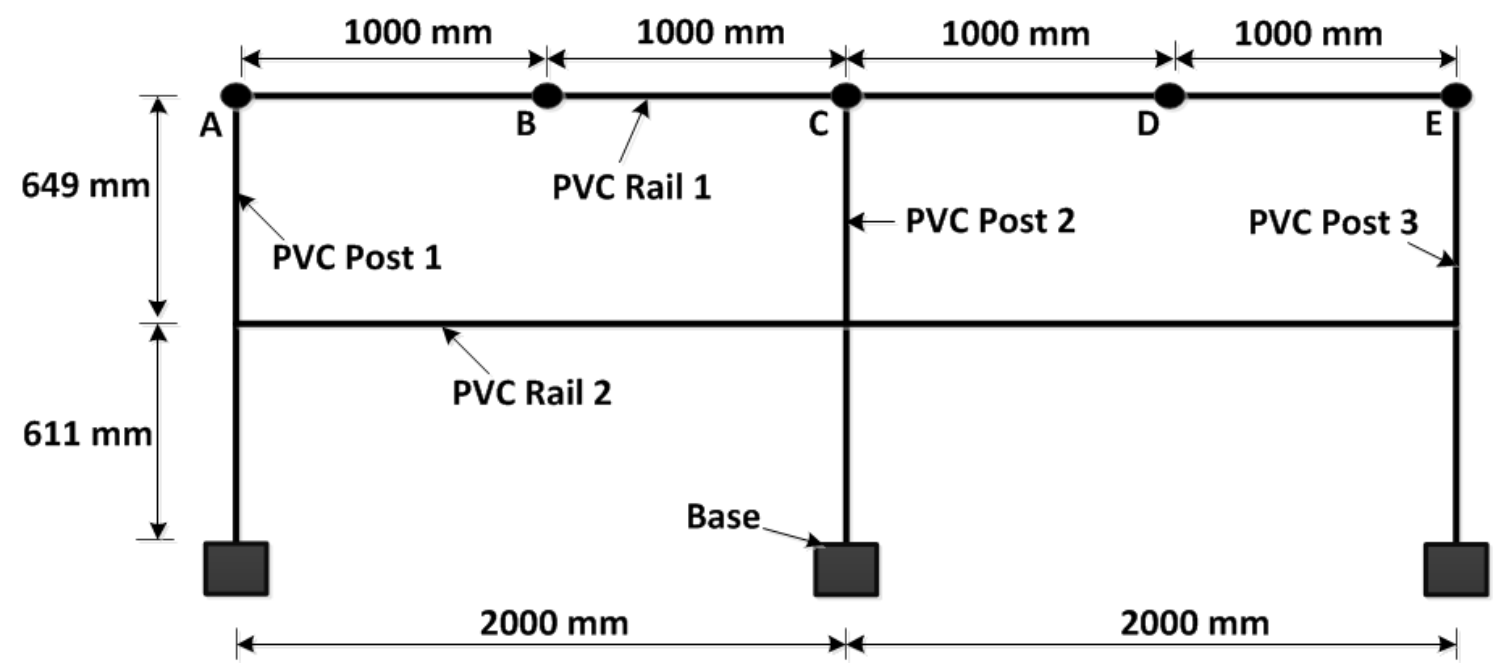

Figure 8: Overall geometry of the first PVC post and rail fence showing the locations of Nodes A - E used in the subsequent FE analyses (post spacing $=2000 \mathrm{~mm}$ )

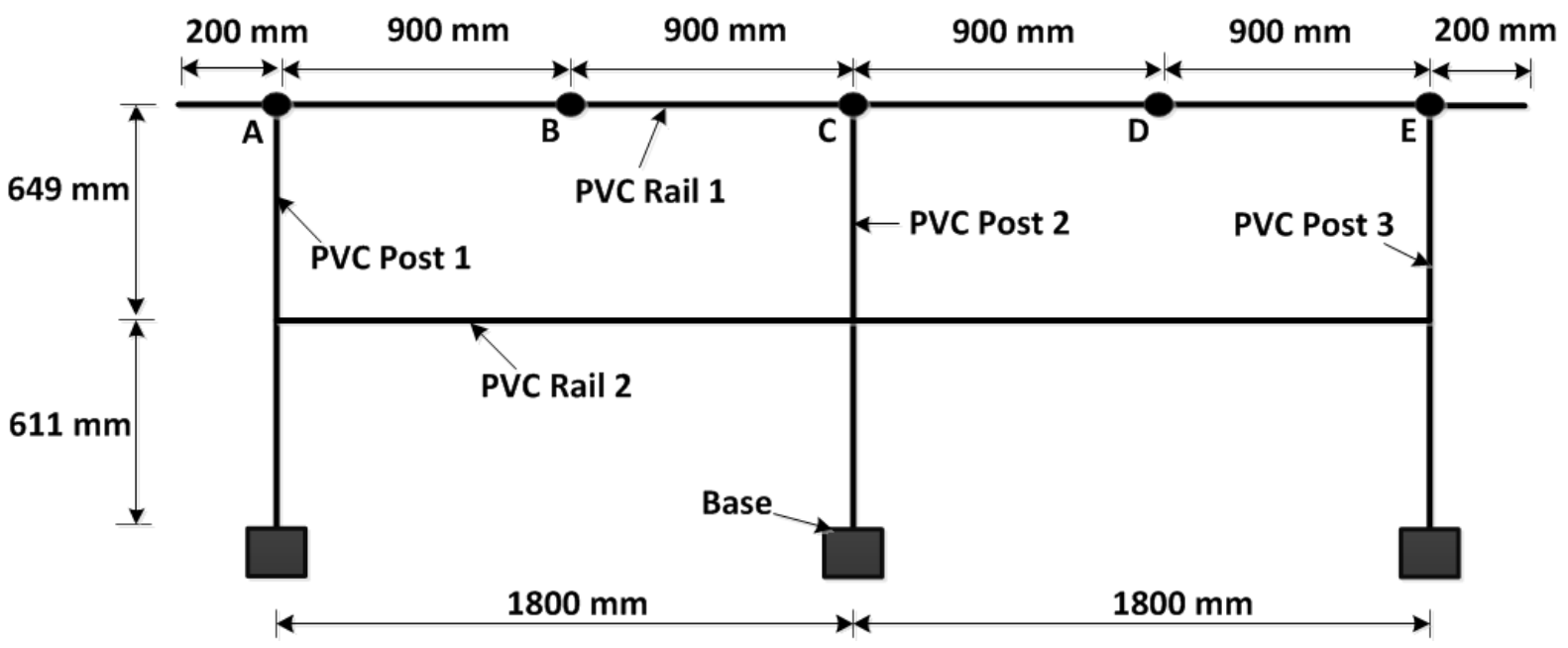

Figure 9: Overall geometry of the second PVC post and rail fence showing the locations of Nodes A - E used in the subsequent FE analyses (post spacing $=1800 \mathrm{~mm}$ ) 
Figure 10 shows the loading arrangement for the load-deflection tests on the two-bay PVC fence. The load was applied normal to the plane of the fence at the top of the centre post (Node C) of the fence, and subsequently at the mid-bay points (Nodes B and D in Figure 8 and Figure 9). A horizontal line load was applied at Node C (105 mm below the top of the post and level with the centre line of the rail) via a circular steel rod attached to a $2.5 \mathrm{kN}$ load cell (see Figure 11). Figure 12 shows a close-up view of the vertical line loading adopted at the mid-spans of the top rail.

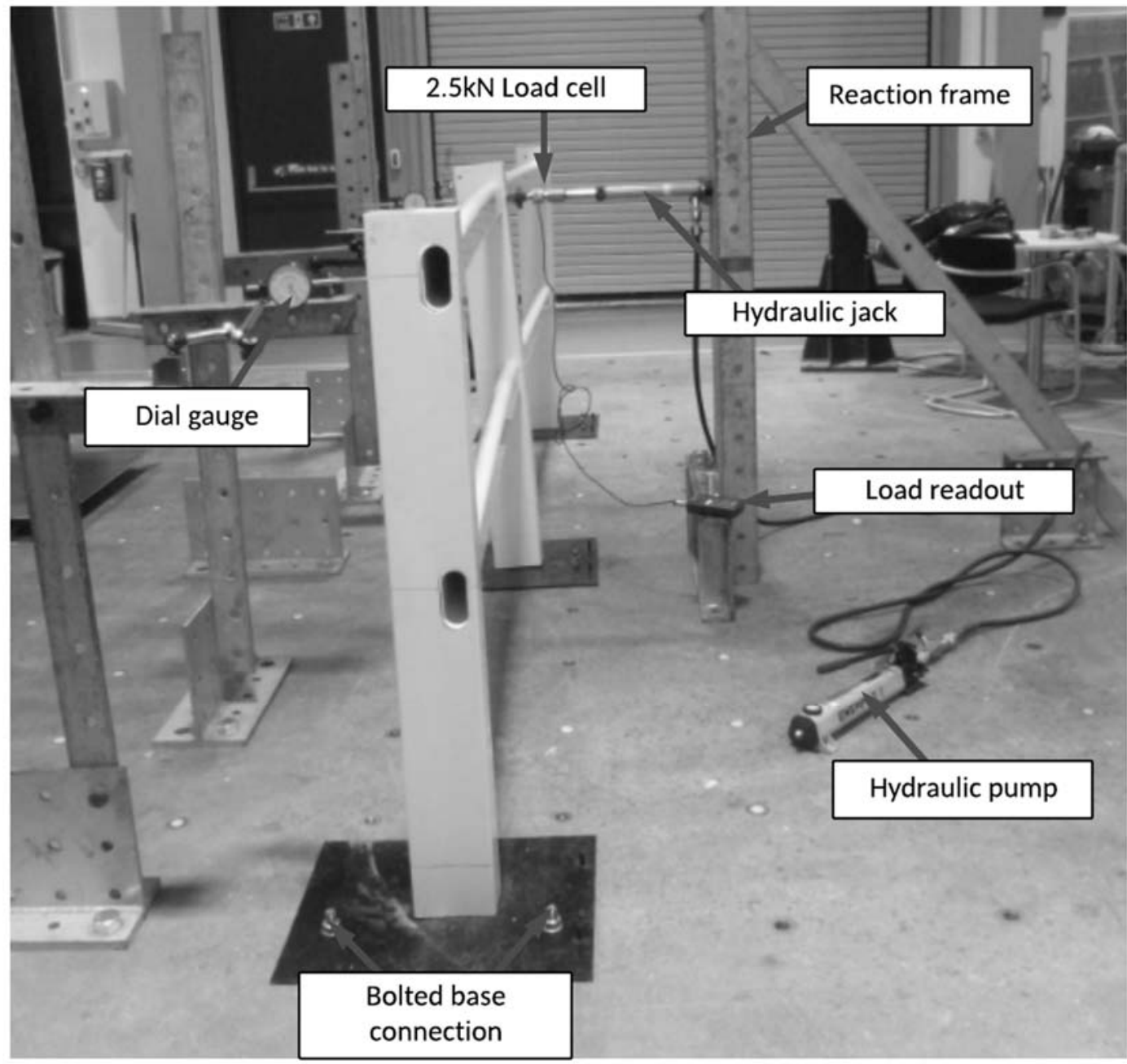

Figure 10: Load test on the two-bay PVC fence with a $2000 \mathrm{~mm}$ post spacing

The loads were applied in increments of $100 \mathrm{~N}$ up to a maximum load of $600 \mathrm{~N}$. The latter value was determined from several preliminary load tests on the fence to ensure that the load-deflection response was linear elastic. Several authors (Bakis et al. 2002, Satasivam and Bai 2014) have also highlighted that the serviceability design of structures is often more critical than strength design. 
Three dial gauges were placed in contact with the back of the posts (Nodes A, C and E), and two dial gauges were in contact with the back of the top rail at their mid-bay points (Nodes B and $D)$ to record horizontal deflections for each load increment. The load-deflection tests were repeated three times.

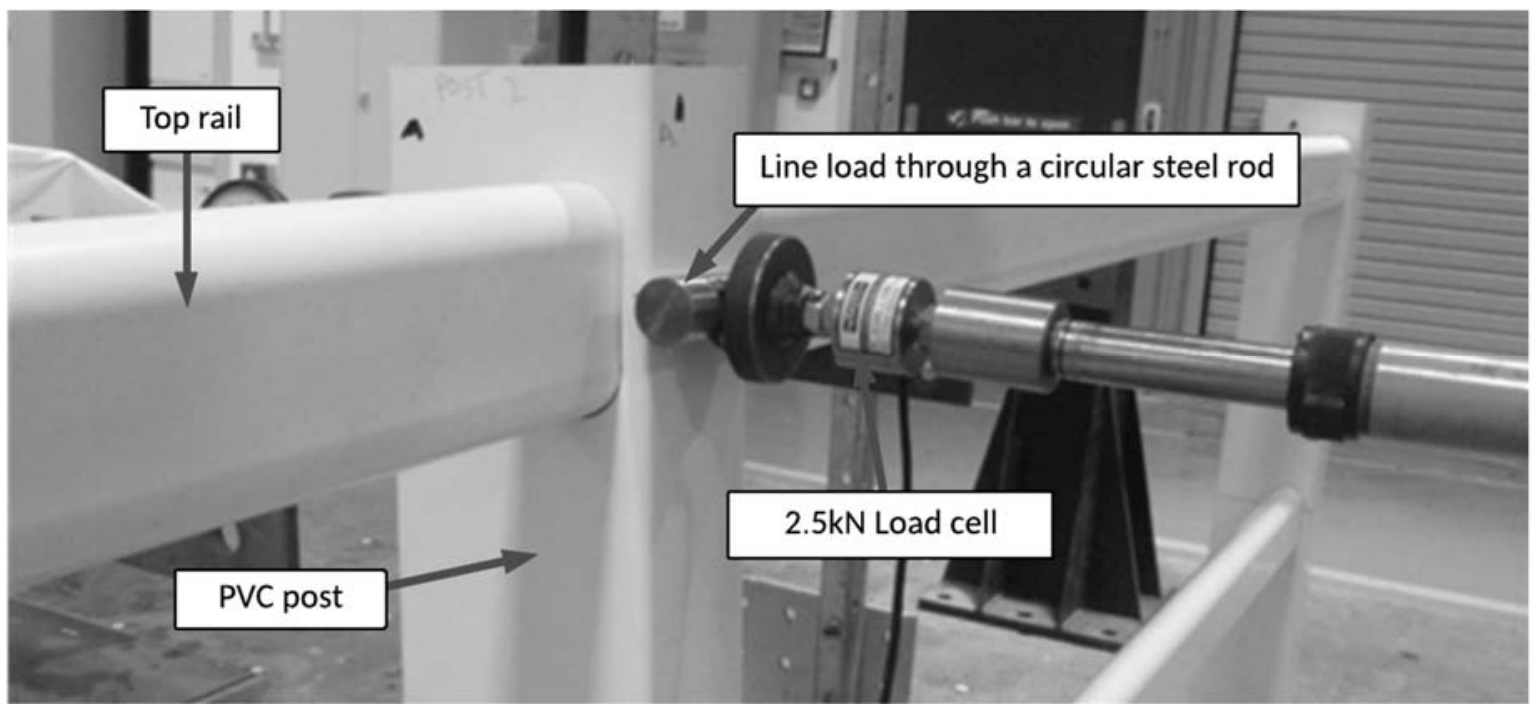

Figure 11: Close-up view of the loading arrangement on the centre post of the PVC fence (Node C)
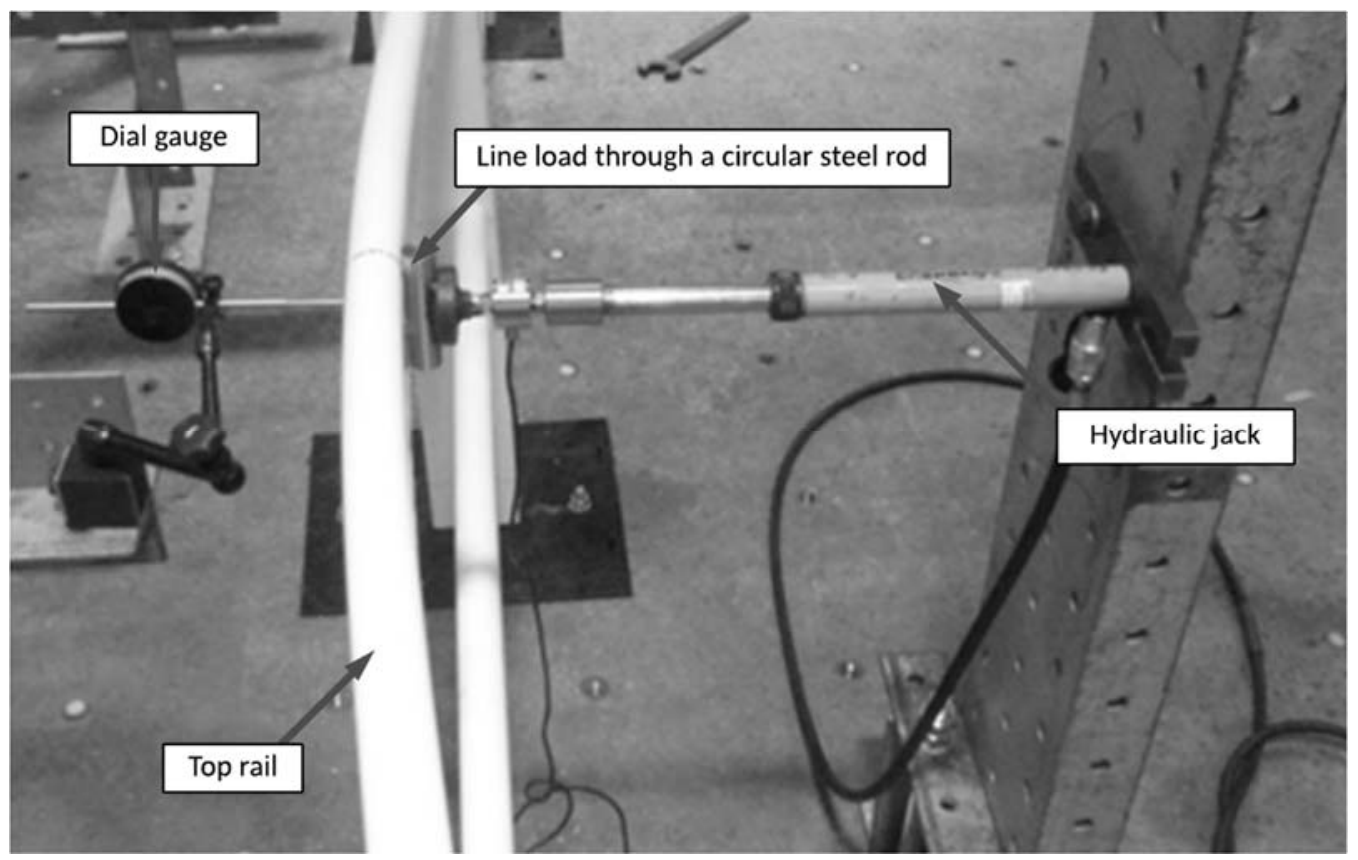

Figure 12: Close-up view of the loading arrangement at the mid-bay point of the top rail (Node B) of the PVC fence

5. Results and Discussion of the Load-Deflection Tests on the Two-Bay PVC Fences 
Figure 13 and Figure 14 show images of the deformations of the PVC fence with a post spacing of $2000 \mathrm{~mm}$, when subjected to the maximum load of $600 \mathrm{~N}$ applied at Nodes B and C, respectively. There was a small upward movement of the bottom of the centre PVC post from the bolted steel base plate when the loading was applied at the centre post (see Figure 15). A similar situation was observed with the centre post and the outer post closer to the loading point, when loading was applied at one of the mid-bay points.

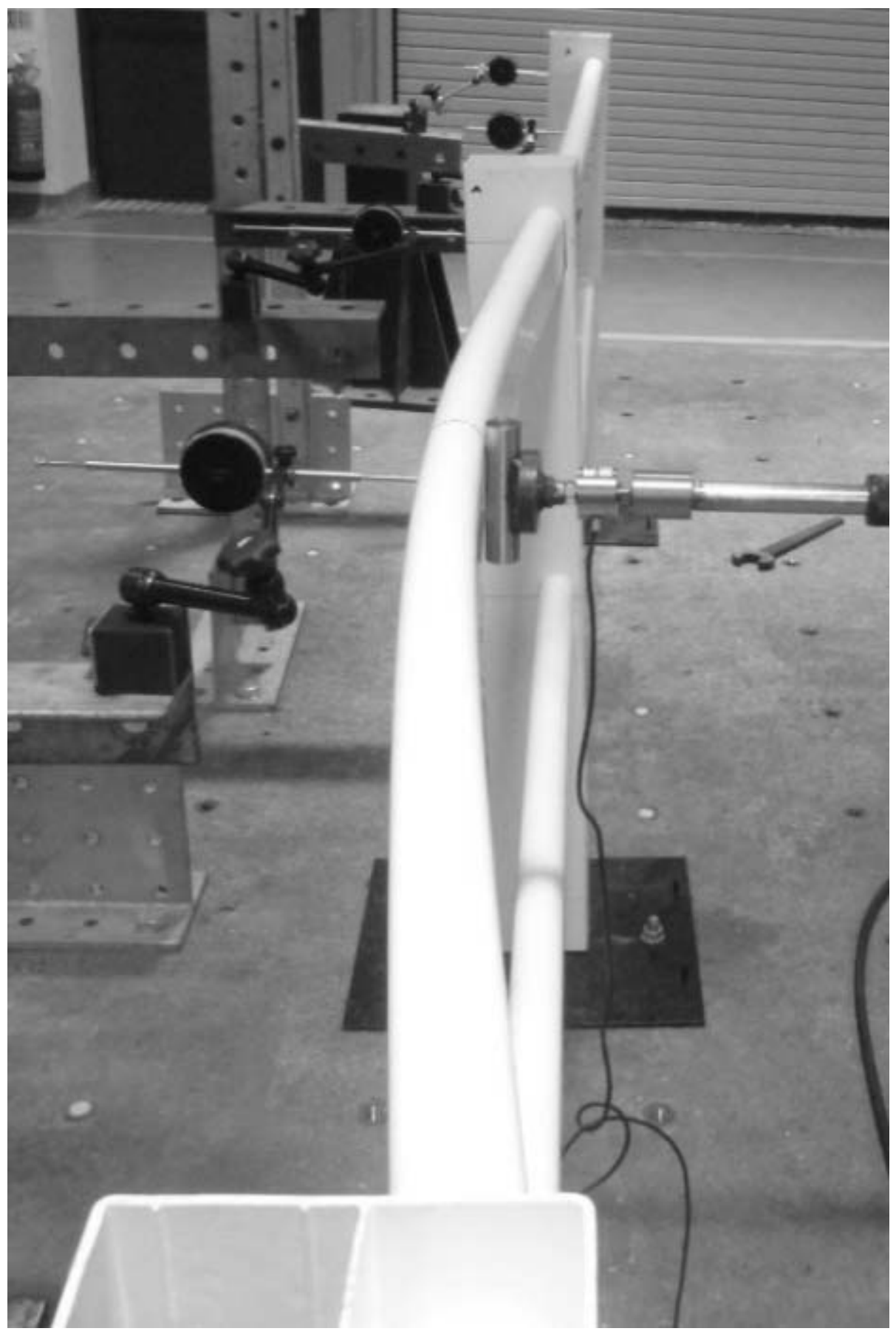


Figure 13: The two-bay PVC fence with a post spacing of $2000 \mathrm{~mm}$ supporting a maximum load of $600 \mathrm{~N}$ applied at Node B (top rail)

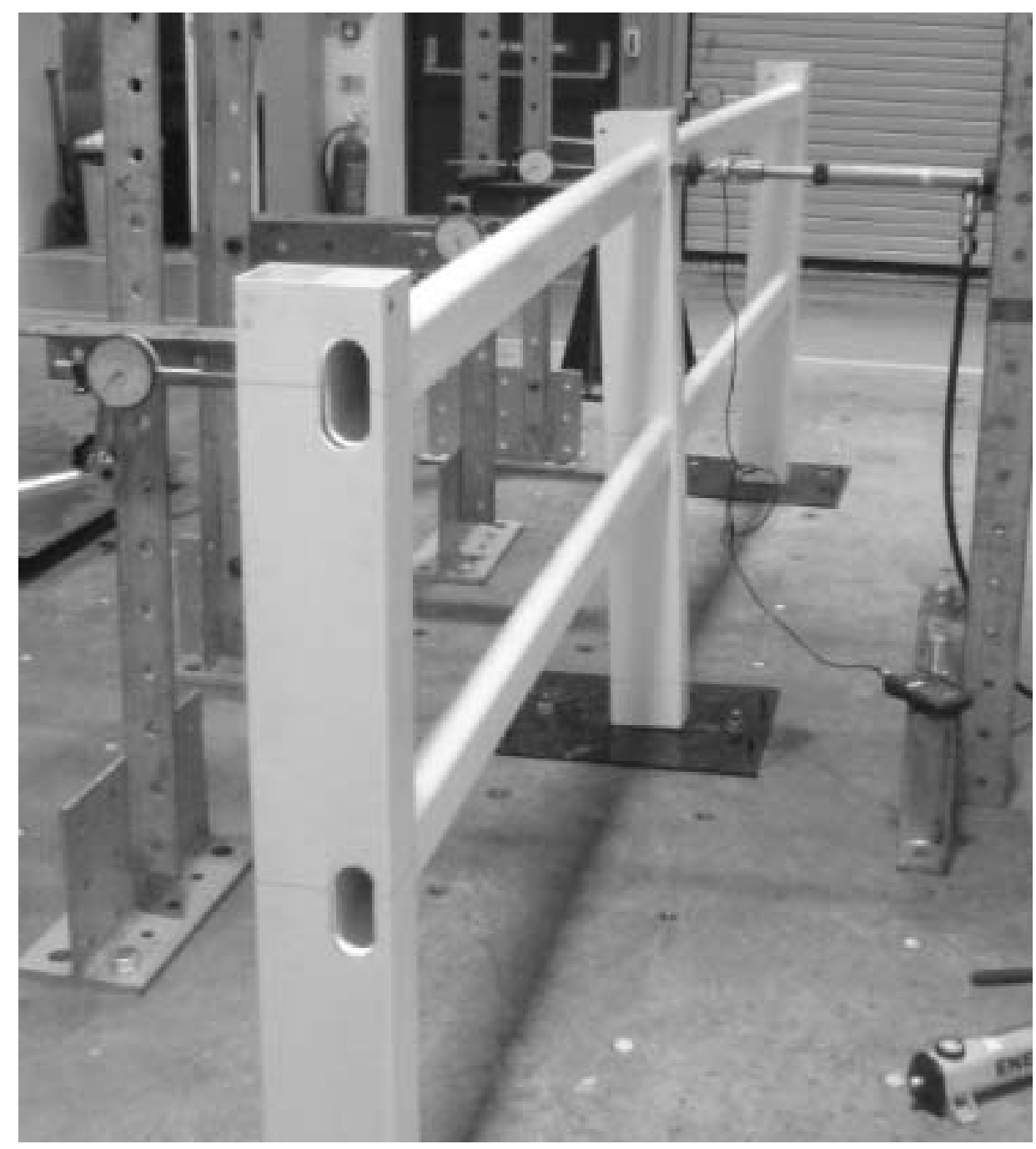

Figure 14: The two-bay PVC fence with a post spacing of $2000 \mathrm{~mm}$ supporting a maximum load of $600 \mathrm{~N}$ applied at Node $\mathrm{C}$ (centre post)

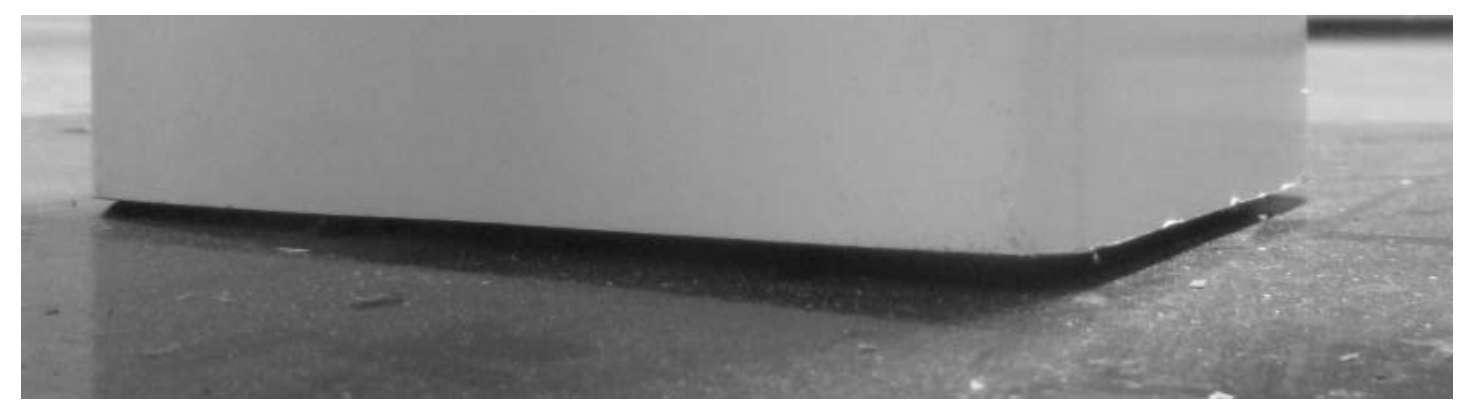

Figure 15: Image showing the separation between the bottom of the centre PVC post and steel base plate when a load of $600 \mathrm{~N}$ was applied at Node $\mathrm{C}$ 
Figure 16, Figure 17 and Figure 18 show plots of the load versus average deflection responses at Nodes A - E of the two-bay PVC fence with a post spacing of $2000 \mathrm{~mm}$ when the load is applied at Nodes B, C and D, respectively.

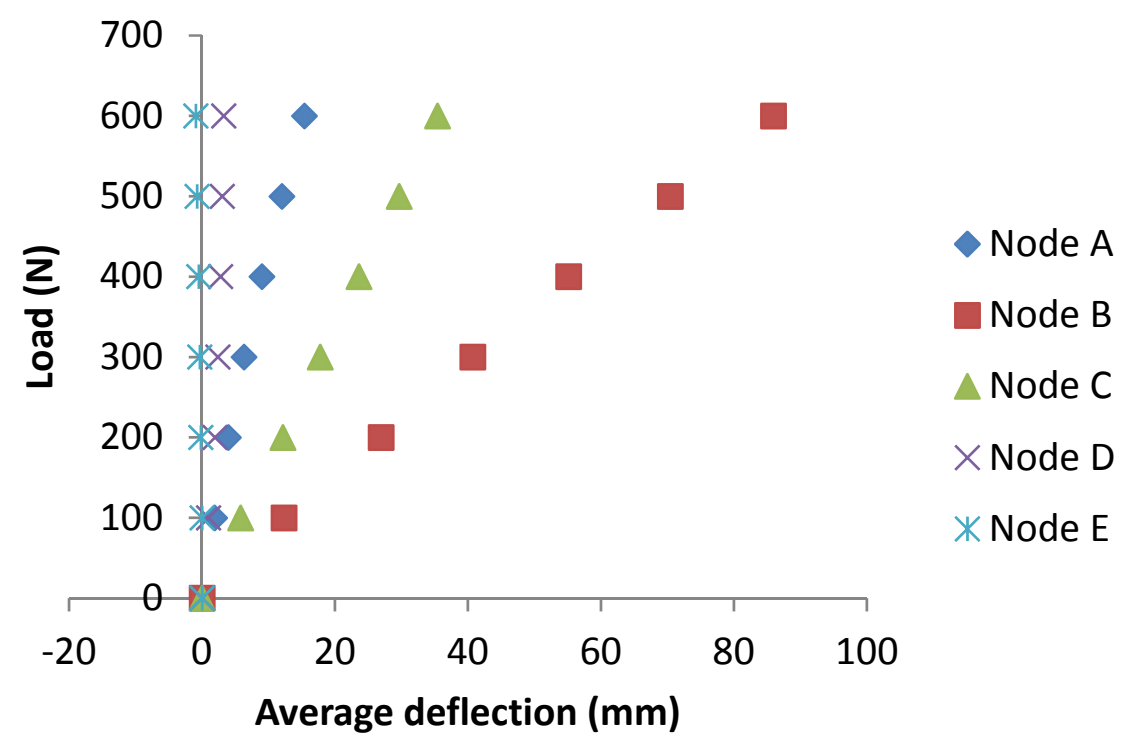

Figure 16: Load versus average deflection responses at Nodes A - E of the two-bay PVC fence loaded at Node B (post spacing $=2000 \mathrm{~mm}$ )

The results for all the tests on the two-bay fence were linear and showed good repeatability. The fence also supported the maximum load of $600 \mathrm{~N}$ without showing any signs of damage. The load versus average deflection responses at Nodes A - E of the fence with a post spacing of $1800 \mathrm{~mm}$ loaded at Nodes B, C and D are similar to those shown in Figure 16, Figure 17 and Figure 18, though, of course, the magnitudes of the deflections were different. 


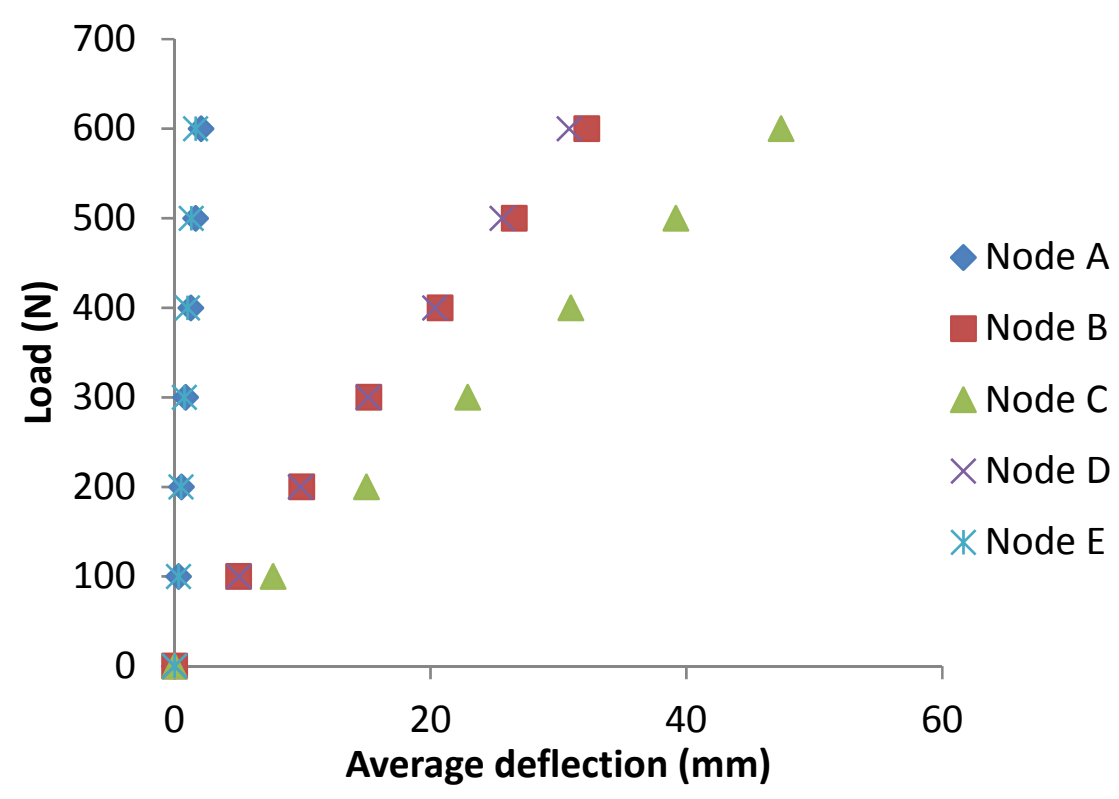

Figure 17: Load versus average deflection responses at Nodes $A-E$ of the two-bay PVC fence loaded at Node C (post spacing $=2000 \mathrm{~mm}$ )

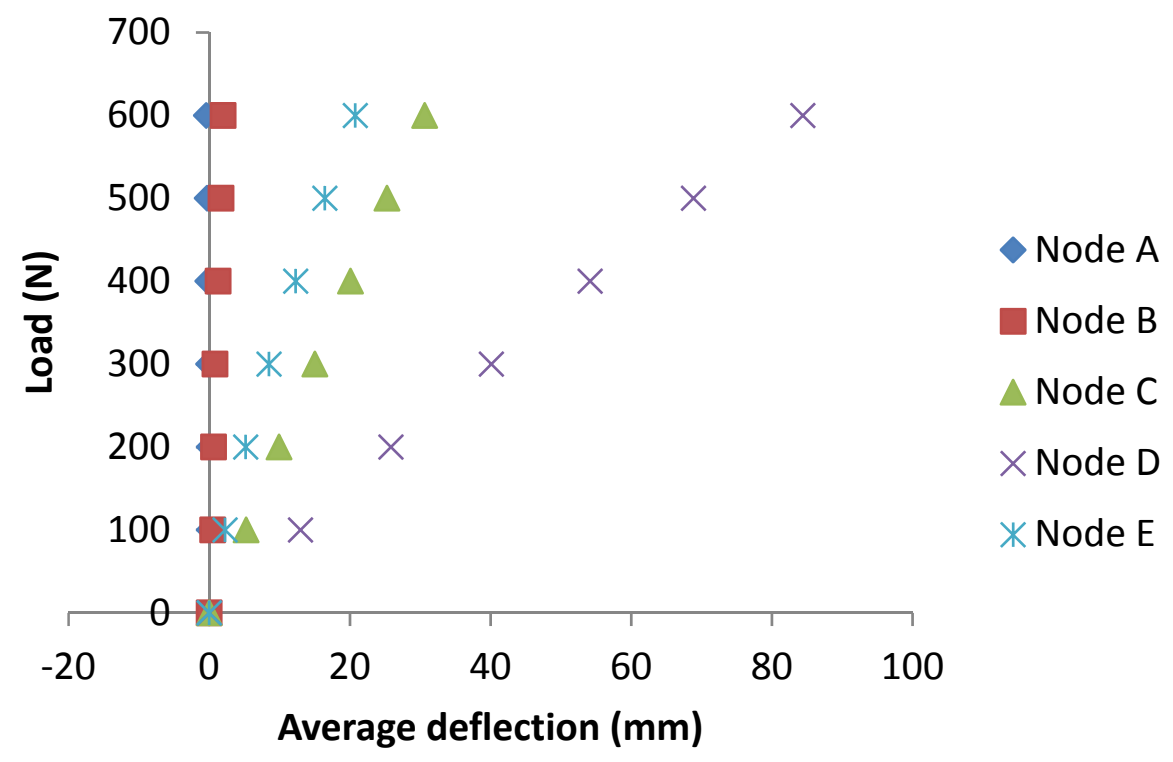

Figure 18: Load versus average deflection responses at Nodes A - E of the two-bay PVC fence loaded at Node $D$ (post spacing $=2000 \mathrm{~mm}$ )

The average transverse deflections corresponding to the maximum load of $600 \mathrm{~N}$ at Nodes $\mathrm{A}$ - E for both sets of load tests are given in Table 2. As expected, the largest deflections occurred at the nodes where the load was applied. For the first set of load tests $(2000 \mathrm{~mm}$ post spacing), the largest deflections corresponding to the maximum load of $600 \mathrm{~N}$ applied at Nodes B, C and D were $85.9 \mathrm{~mm}, 47.4 \mathrm{~mm}$ and $84.4 \mathrm{~mm}$, respectively (see Table 2). Similarly, the largest deflections corresponding to the maximum load at Nodes B, C and D obtained 
from the second set of load tests (1800 mm post spacing) were $65.8 \mathrm{~mm}, 42.9 \mathrm{~mm}$ and 68.9 $\mathrm{mm}$, respectively. These results show that greater deflections were obtained when the fence was loaded at the mid-bay points (Node B and D) compared to the centre post (Node C).

Table 2: Transverse deflections of the two-bay PVC fence at Nodes A - E at the maximum load of $600 \mathrm{~N}$

\begin{tabular}{|c|c|c|c|c|c|c|}
\hline \multirow{2}{*}{ Tests } & $\begin{array}{c}\text { Loading } \\
\text { point }\end{array}$ & \multicolumn{5}{|c|}{ Average transverse deflection } \\
\cline { 3 - 7 } & & Node A & Node B & Node C & Node D & Node E \\
\cline { 2 - 7 } & Node B & 15.4 & 85.9 & 35.4 & 3.3 & -0.9 \\
\hline \multirow{2}{*}{$\begin{array}{c}\text { First set } \\
\text { (post } \\
\text { spacing }= \\
2000 \mathrm{~mm} \text { ) }\end{array}$} & Node C & 2.1 & 32.2 & 47.4 & 30.8 & 1.6 \\
\cline { 2 - 7 } & Node D & -0.2 & 2.0 & 30.6 & 84.4 & 20.8 \\
\hline $\begin{array}{c}\text { Second set } \\
\text { (post } \\
\text { spacing }= \\
1800 \mathrm{~mm} \text { ) }\end{array}$ & Node B & 23.1 & 65.8 & 30.3 & 5.9 & -0.7 \\
\cline { 2 - 7 } & Node C & 5.1 & 29.1 & 42.9 & 26.5 & 4.4 \\
\cline { 2 - 7 } & Node D & -0.1 & 5.1 & 28.9 & 68.9 & 27.9 \\
\hline
\end{tabular}

The transverse deflections recorded at Node C for a load of $600 \mathrm{~N}$ applied at Node $\mathrm{C}$ were used to determine the relative transverse stiffnesses for both sets of load tests on the twobay PVC fences. The transverse deflections were $47.4 \mathrm{~mm}$ and $42.9 \mathrm{~mm}$ for the first and second set of tests, respectively. Dividing the maximum load of $600 \mathrm{~N}$ applied at Node $\mathrm{C}$ by the transverse deflection at the same node, gave transverse stiffnesses of $12.7 \mathrm{~N} / \mathrm{mm}$ and 14 $\mathrm{N} / \mathrm{mm}$ for the first and second set of tests, respectively. The test results showed that a reduction in the distance between the PVC posts from $2000 \mathrm{~mm}$ to $1800 \mathrm{~mm}$ resulted in an approximate $10 \%$ increase in the relative transverse stiffness of the fence.

In the second set of load tests on the PVC fence with a post spacing $(1800 \mathrm{~mm})$, i.e. equal to that of the two-bay timber fence reported in Sotayo et al. (2016), the heights of the PVC posts (1260 mm) were $40 \mathrm{~mm}$ lower than those of the timber fence. Nevertheless, comparisons of the transverse stiffnesses were made between the timber fence results in Sotayo et al. (2016) and the second set of PVC fence results. The relative transverse stiffnesses of the two-bay timber and PVC fences were $50.7 \mathrm{~N} / \mathrm{mm}$ and $14.0 \mathrm{~N} / \mathrm{mm}$, respectively. It is also worth mentioning that the PVC fence posts incorporated steel components (a steel base plate and two $600 \mathrm{~mm}$ long steel angles welded to it, as shown in Figure 6) to enhance their flexural stiffnesses and as a means of fixing the posts to the ground. However, based on the 
aforementioned stiffness values, it is evident that the transverse stiffness of the two-bay timber fence is approximately $262 \%$ greater than that of the PVC fence.

Figure 19 shows a plot of the transverse deflections at Nodes A - E of the two-bay PVC fence when a load of $600 \mathrm{~N}$ was applied at Node C. For both sets of tests, when the load was applied at Node $\mathrm{C}$, the deflections at Node A were approximately $31 \%$ and $16 \%$ greater than those at Node $E$ for the first and second set of tests, respectively (see Table 2 and Figure 19). It would be expected that the deflections of the nodes at opposite ends of the top rail should be equal. However, the deflections at Node B were approximately $5 \%$ and $10 \%$ greater than those at Node $\mathrm{D}$ for the first and second set of tests, respectively, thereby reflecting a smaller difference compared to those at Nodes $\mathrm{A}$ and $\mathrm{E}$.

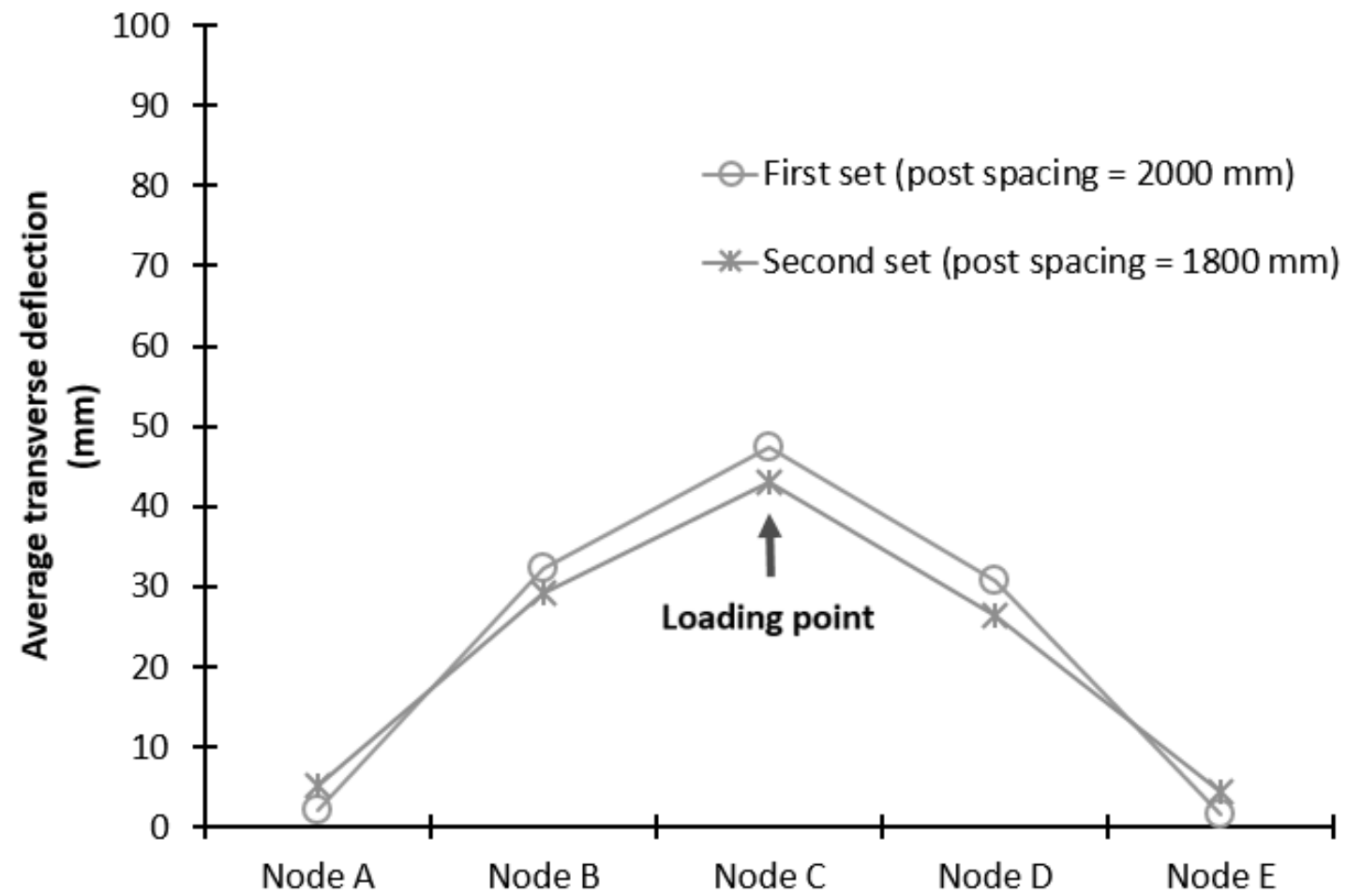

Figure 19: A plot of the average transverse deflections at Nodes A - E of the two-bay PVC fence when a load of $600 \mathrm{~N}$ was applied at Node $\mathrm{C}$

Figure 20 and Figure 21 show plots of the average transverse deflections at Nodes A-E of the two-bay PVC fence when a load of $600 \mathrm{~N}$ was applied at Nodes B and D, respectively. The maximum load of $600 \mathrm{~N}$ at Node $\mathrm{B}$ gave maximum deflections of $85.9 \mathrm{~mm}$ and $65.8 \mathrm{~mm}$ in the first and second set of tests, respectively, i.e. a $23 \%$ difference (see Table 2 and Figure 20). Similarly, deflections of $84.4 \mathrm{~mm}$ and $68.9 \mathrm{~mm}$ at Node D were obtained from the first and second set of tests, respectively with the maximum load of $600 \mathrm{~N}$ at Node $\mathrm{D}$ (see Table 2 and 
Figure 21). These values show that the latter was about $18 \%$ smaller than the former. In addition, Node A's small deflection of $0.2 \mathrm{~mm}$ was in the opposite direction to that of the loading when the maximum load of $600 \mathrm{~N}$ was applied at Node D. A similar situation was observed when the maximum load was applied at Node B, but the deflection at Node $E$ was $0.9 \mathrm{~mm}$ in the opposite direction (see Figure 20 and Figure 21).

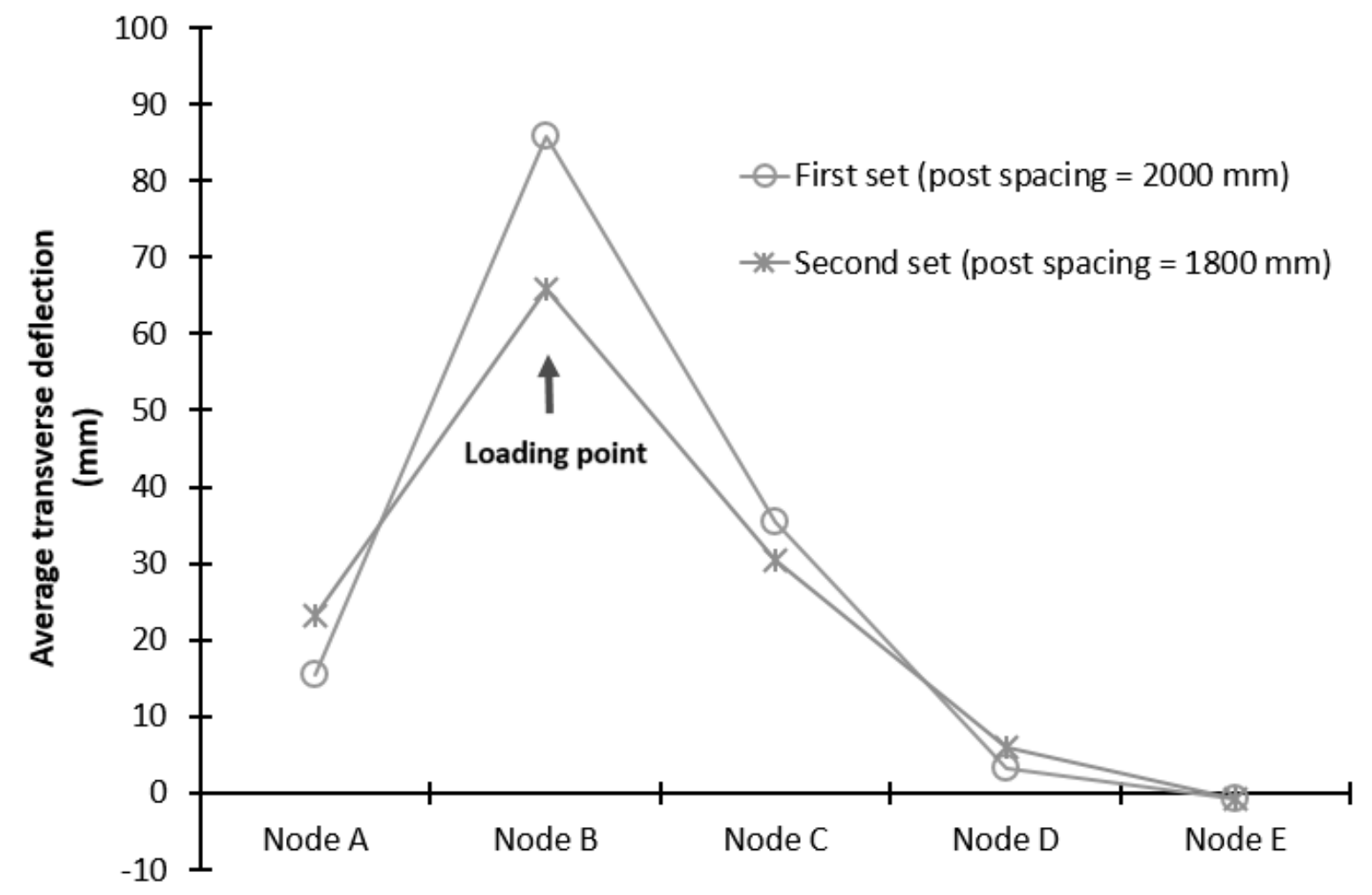

Figure 20: A plot of the average transverse deflections at Nodes A - E of the two-bay PVC fence when a load of $600 \mathrm{~N}$ was applied at Node B

When the maximum load was applied at Node B (mid-bay point), the deflection at Node A was $56 \%$ lower than that of Node $C$ in the first set of tests (see Figure 20). When subjected to the same loading in the second set of tests, the deflection at Node A was $24 \%$ lower than that at Node C. Furthermore, when load was applied at the other mid-bay point (Node D), the deflections at Node $\mathrm{E}$ were about $32 \%$ and $4 \%$ lower than those at Node $\mathrm{C}$ for the first and second set of tests, respectively (see Figure 21). These test results show that when the load was applied at a mid-bay point, the deflection at the centre post was greater than the deflection at the outer post closer to the loading point (see Figure 20 and Figure 21). However, it was expected that the deflection at the centre post would be smaller than that at the nearer outer post due to the additional transverse stiffness provided by structural continuity from 
the other bay. These differences may be due to variable contact between the inner faces of the PVC posts and the welded steel angles which may have led to different joint stiffnesses at the bases of the PVC posts. It may also be as a result of different separations between the bottom of the centre and outer PVC posts (closer to the loading point) and the bolted steel base plates when loaded at the mid-bay points (see Figure 15).

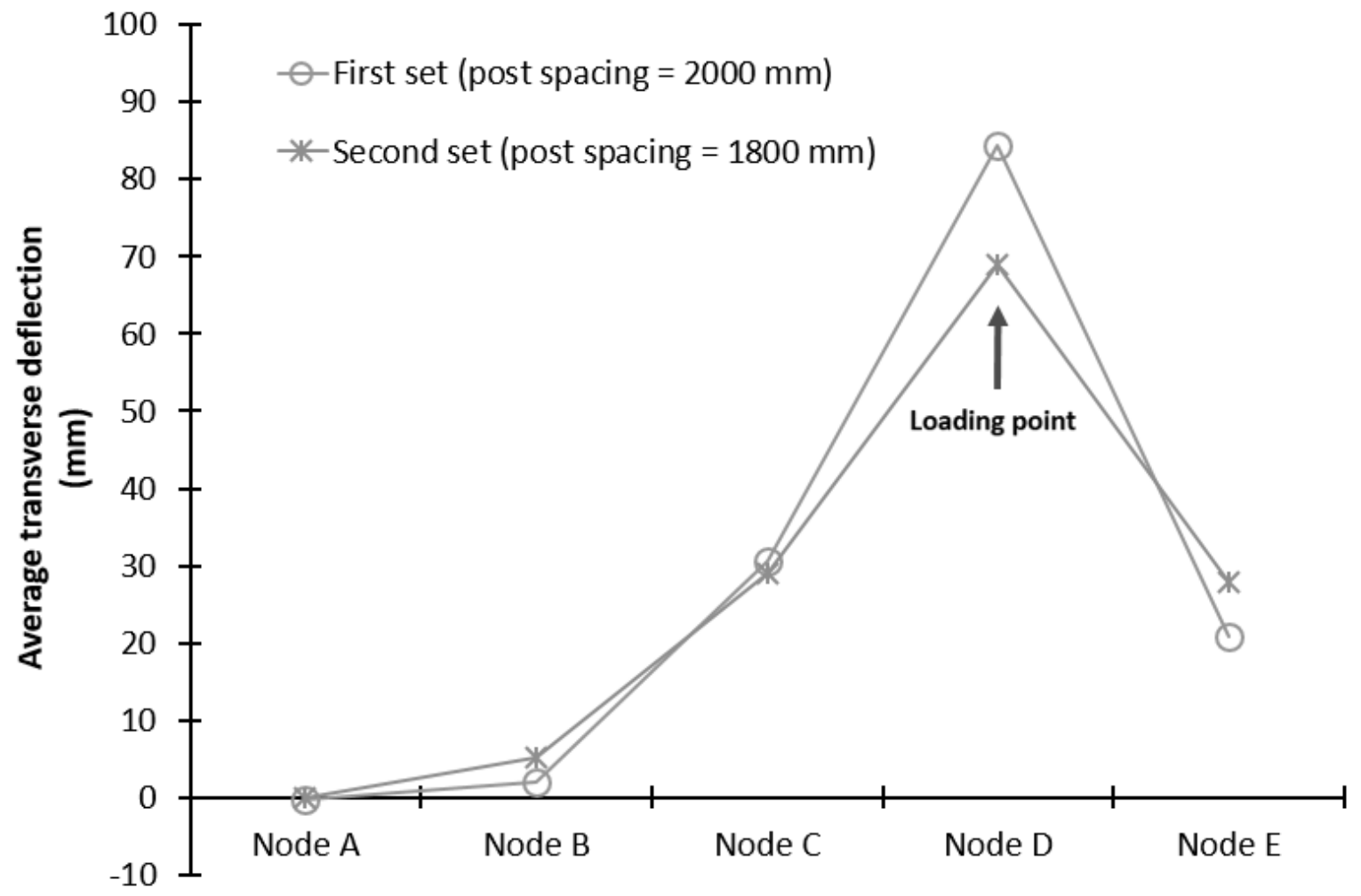

Figure 21: A plot of the average transverse deflections at Nodes A - E of the two-bay PVC fence when a load of $600 \mathrm{~N}$ was applied at Node $D$

Furthermore, it was expected that the deflection at Node A when the load was applied at Node B should be the same as that of Node E when the load was applied at Node D. However, in the first set of tests, when a load of $600 \mathrm{~N}$ was applied at Node $\mathrm{B}$, the deflection at Node $\mathrm{A}$ was $15.4 \mathrm{~mm}$, which is approximately $26 \%$ lower than the deflection at Node E $(20.8 \mathrm{~mm})$ when the same load was applied at Node D. Similarly, the deflection at Node A was about 17 \% lower than the deflection at Node $\mathrm{E}$ when a load of $600 \mathrm{~N}$ was applied at Nodes $\mathrm{B}$ and $\mathrm{D}$, respectively in the second set of tests. These differences can be attributed to the presence of small clearances leading to relative movement (minor slip) at the interfaces between the rail cut-outs of the PVC posts and the edges/faces of the PVC rails. Thus, these slips may have led to limited load re-distribution across the full two-bay PVC fence. 


\section{Finite Element (FE) Model and Analysis}

A commercial FE package (ANSYS Workbench Release 15) was used to investigate the loaddeformation response of the two-bay PVC fence. The overall geometry, loading and boundary conditions of the PVC fence, described in Section 4 (see Figure 8 and Figure 9), formed the basis of the FE analysis carried out in this section.

As the two-bay PVC fence was loaded to produce transverse bending under service loading, only the longitudinal elastic properties of the posts and rails significantly affect the FE simulation results. For simplicity, all of the fence components were modelled as isotropic linear elastic materials, and for computational efficiency, shell elements were used to model the thin-walled PVC and steel angle components. For the material properties, the longitudinal elastic flexural moduli of the PVC posts and rails given in Table 1 were used; the elastic modulus of steel was taken as $210 \mathrm{GPa}$ and the Poisson's ratio for steel and PVC was taken as 0.3 (Callister and Rethwisch 2008). Details of the FE analyses carried out on the two-bay PVC fence are presented, validated and compared with the experimental results given in Section 5.

The auto-mesh function in ANSYS was used to generate SHELL181 elements to model the PVC posts and rails and the welded steel angles and base plates. Figure 22 shows the contact modelled between the inner wall of the PVC post and the steel angles. This region of contact was modelled using contact elements (CONTA174 and TARGE170) and defined with a coefficient of friction of 0.3 (Pakala, Kodur, and Dwaikat 2012, ANSYS Workbench Release 15). These contact elements are typically used to represent contact and sliding between faces in ANSYS (Tsavdaridis and Papadopoulos 2016). Additionally, the pairs of holes on each baseplate were fully constrained (rigidly fixed) against translational and rotational motions (see Figure 22).

The six rail-to-post connections of the two-bay PVC fence were also modelled using CONTA174 and TARGE170 elements. Complete contacts between the cut-outs in the PVC posts and the faces of the PVC rails were also defined with a coefficient of friction of 0.3 (Pakala, Kodur, and Dwaikat 2012, ANSYS Workbench Release 15). In the FE model, a load of $600 \mathrm{~N}$ was applied at Nodes B, C and D (see Figure 8) normal to the plane of the PVC fence. A mesh convergence study was carried out, resulting in an optimised mesh of 10,153 elements. 
This optimised mesh was used in the analyses of the two-bay PVC fence, and is shown in Figure 23.

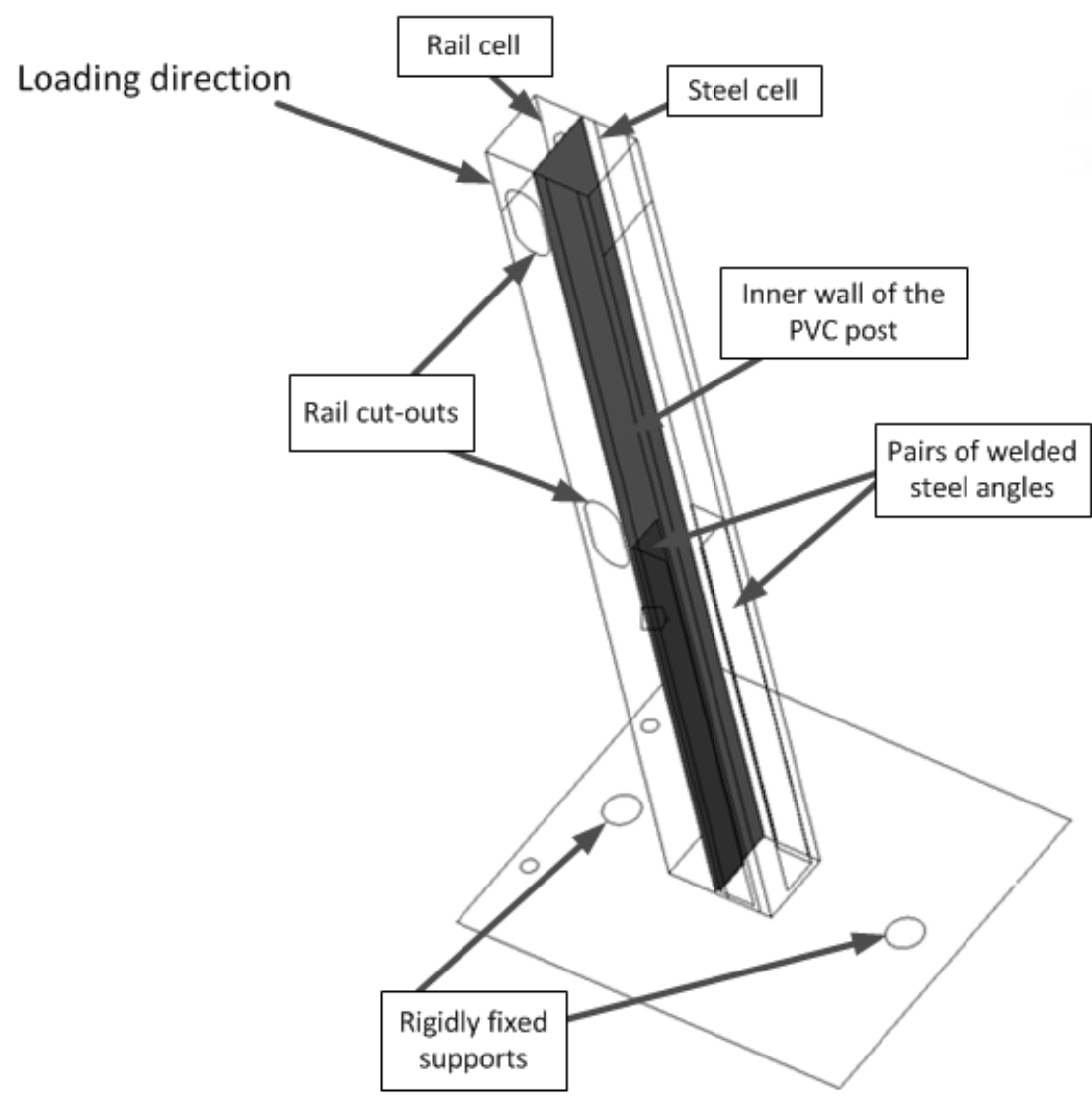

Figure 22: The FE model boundary conditions showing contact between the inner wall of the PVC post (red) and the corresponding surface on the steel angle of the base-plate assembly (blue) and also the location of the rigidly fixed supports on the base-plate 


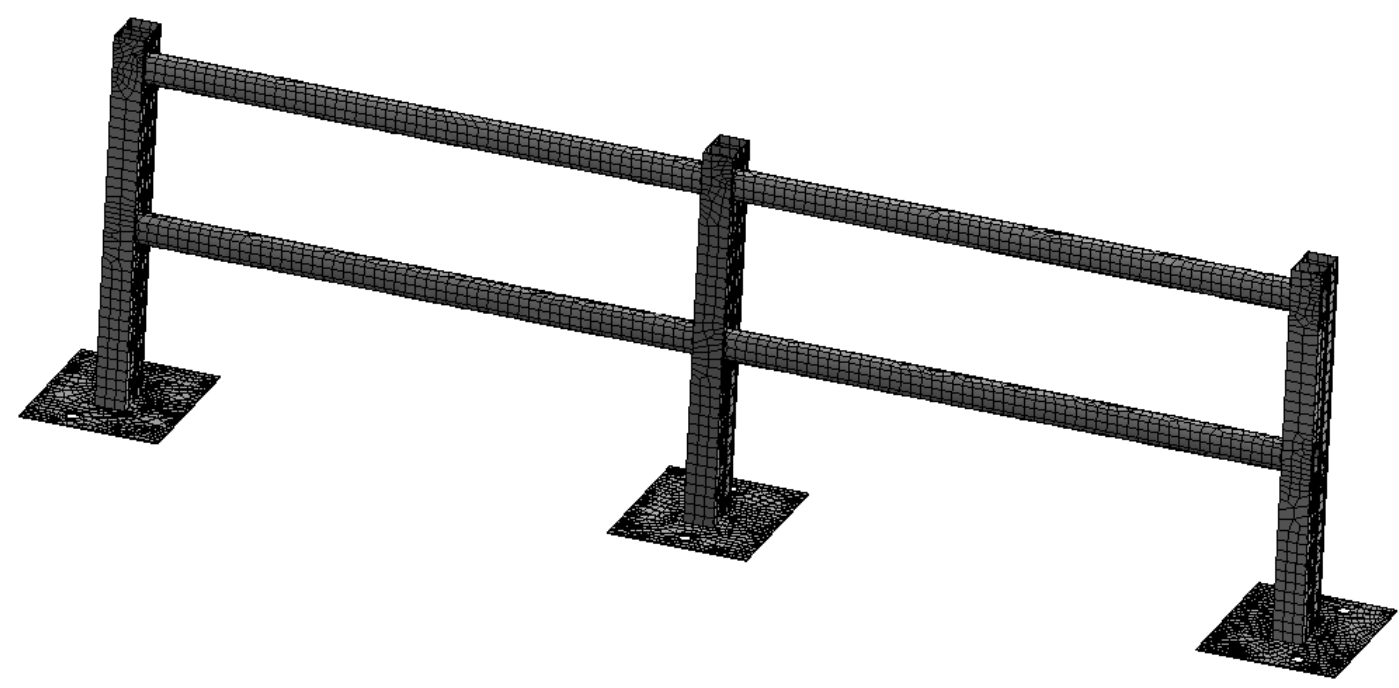

Figure 23: FE mesh used to analyse the load-deflection behaviour of the two-bay PVC fence

\section{Analysis and Discussion of the FE and Experimental Results}

Figure 24 shows an FE contour plot of the transverse deflection of the two-bay PVC fence for a load of $600 \mathrm{~N}$ applied near the top of the centre post. The deformation modes predicted by the FE analysis are in good agreement with those observed in the experimental tests. When the load was applied at Node C (centre post), the deformation mode predicted by the FE analysis is shown in Figure 24, and compares well with the experimental mode shown earlier in Figure 14. Similarly, the deformation modes observed in the tests on the two-bay PVC fence with the loads applied at Node B (cf. Figure 13 from Section 5) and Node D (not shown) are similar to those shown in Figure 25 and Figure 26 for a load of 600 N, respectively.

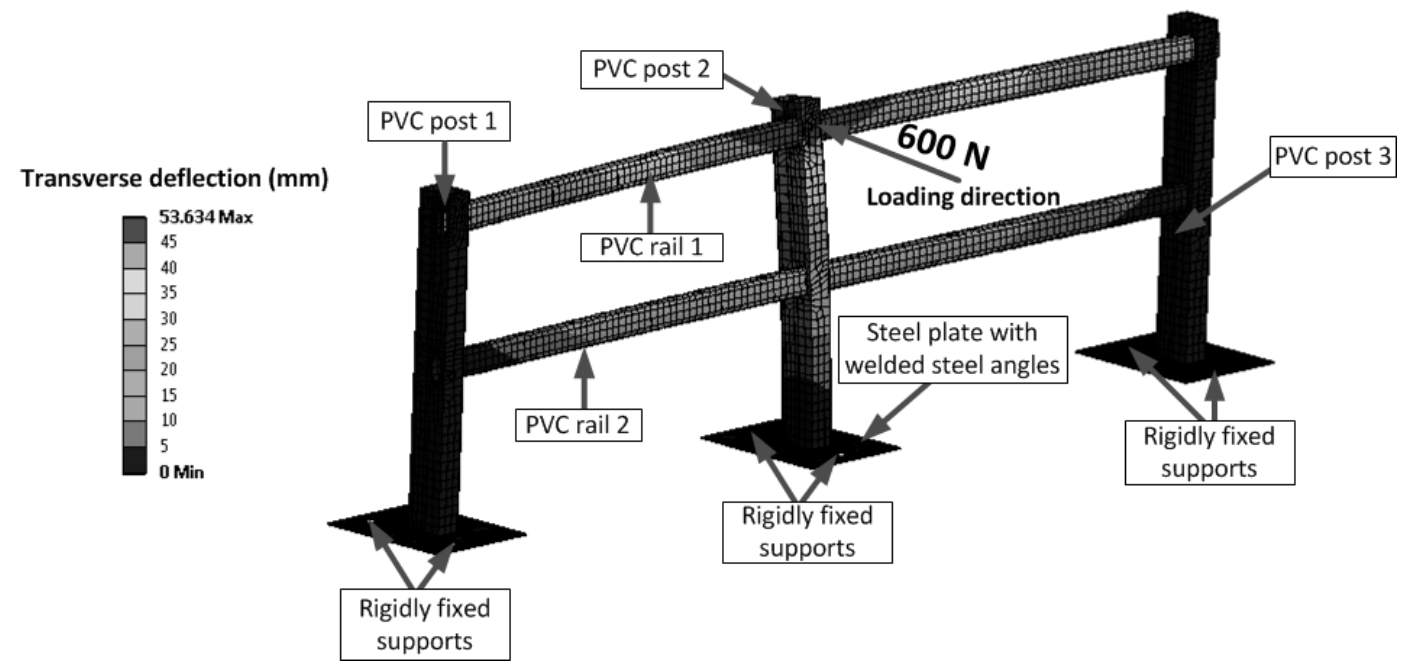

Figure 24: Contour plot showing the transverse deflection of the two-bay PVC fence for a maximum load of $600 \mathrm{~N}$ applied at Node $\mathrm{C}$ (centre post) 


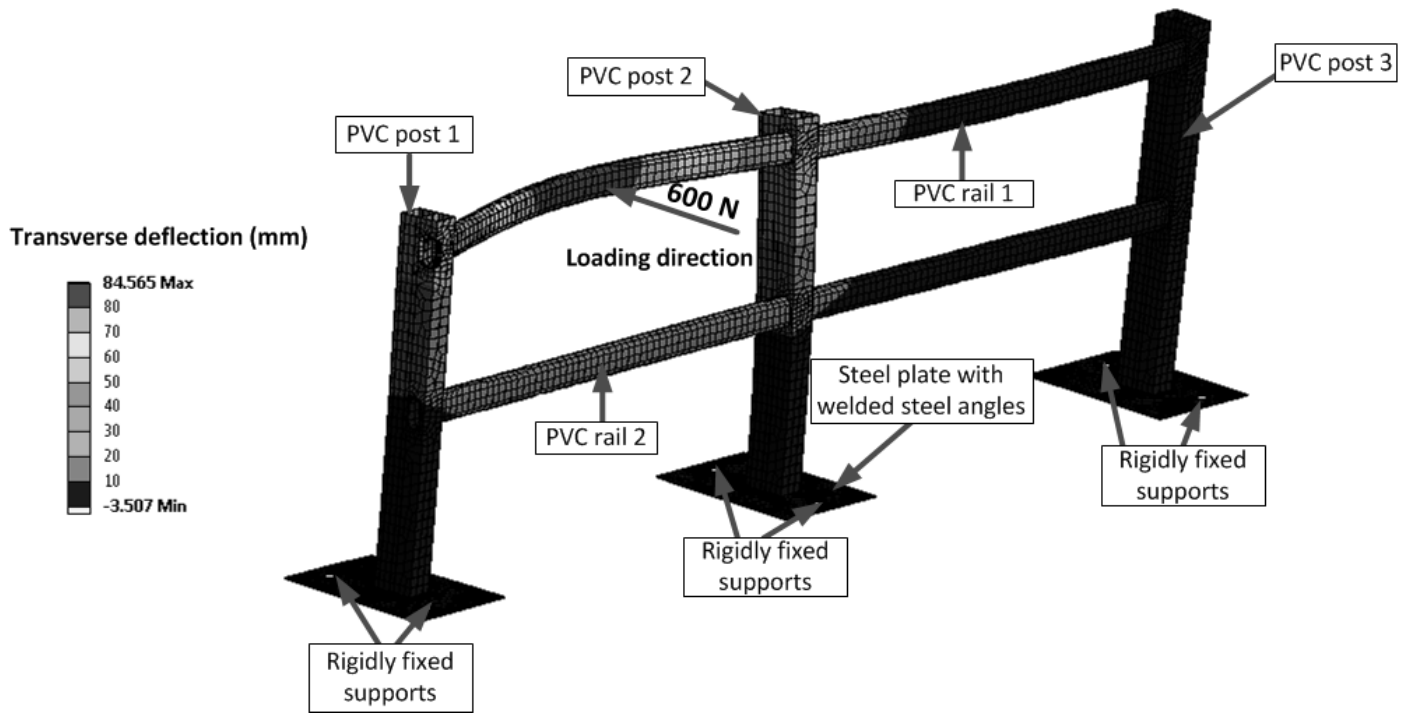

Figure 25: Contour plot showing the transverse deflection of the two-bay PVC fence for a maximum load of $600 \mathrm{~N}$ applied at Node B (mid-bay point of the top rail)

Table 3 shows the transverse deflection of the FE model for the two-bay PVC fence compared with the experimental deflections for loads of $600 \mathrm{~N}$ applied at the centre post (Node $\mathrm{C}$ ) and mid-bay points (Nodes B and D). It is evident that the FE model and test values are in good agreement. When the load is applied at Node C, the FE model deflection at Node C is $6 \%$ lower than the experimental deflection. The FE deflections at Nodes B and D are almost equal to the experimental deflections when the load is applied at Node C, whereas, greater discrepancies of about $20 \%$ are shown at Nodes A and E (outer posts). However, it should be appreciated that the actual differences in the deflections predicted by the FE model and the average experimental tests results were $0.5 \mathrm{~mm}$ and $0.3 \mathrm{~mm}$ for Nodes $A$ and $E$, respectively, which are rather small. In general, the deflections predicted by the FE model at Nodes A - E when the load was applied at Node C, vary from approximately $10 \%$ lower to $20 \%$ higher than the experimental deflections (see Table 3). 


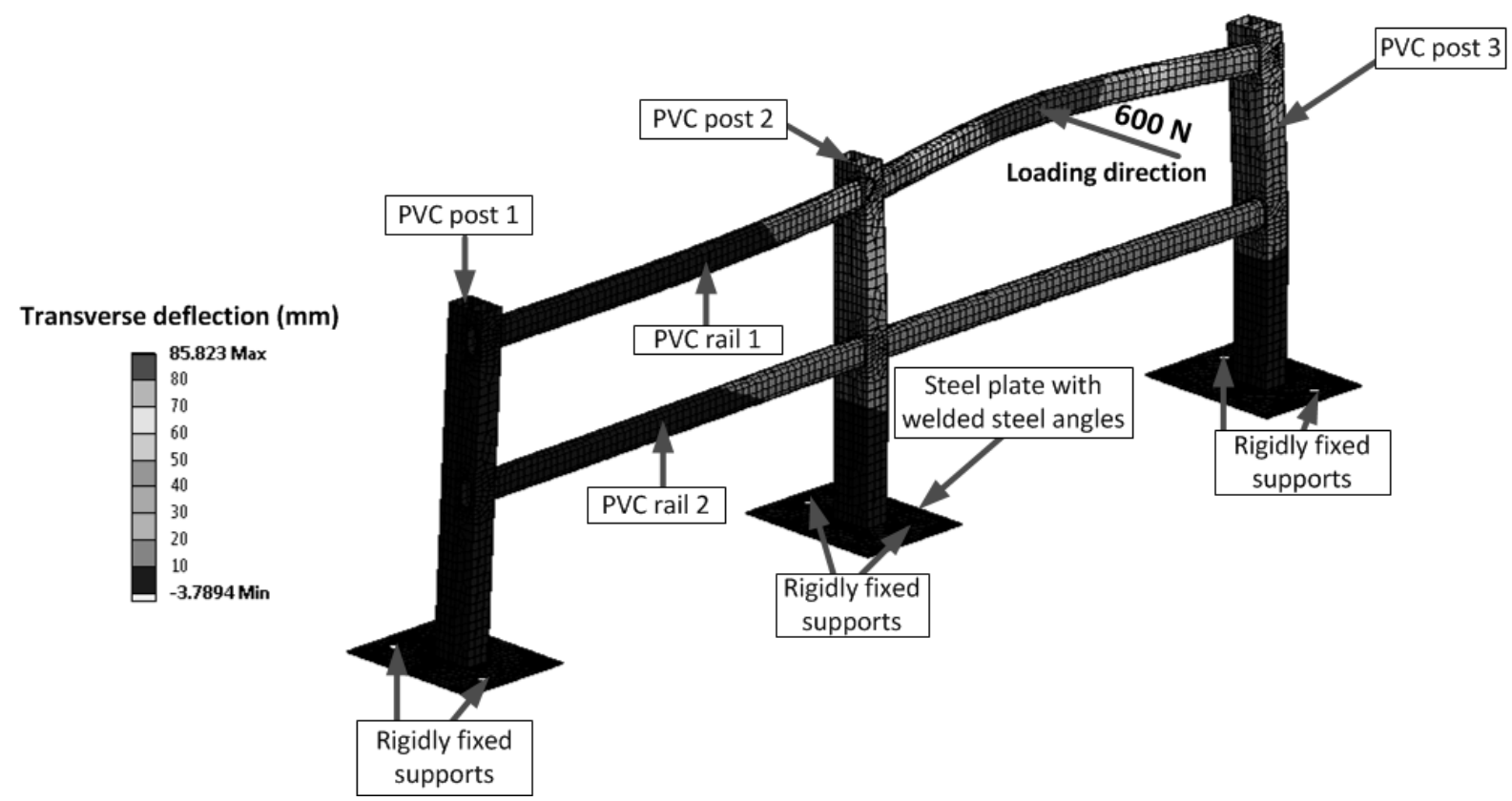

Figure 26: Contour plot showing the transverse deflection of the two-bay PVC fence for a maximum load of $600 \mathrm{~N}$ applied at Node $\mathrm{D}$ (mid-bay point of the top rail) 
Table 3: Comparison of the two-bay PVC fence FE model and the experimental transverse deflections at Nodes A - E for a maximum load of $600 \mathrm{~N}$ applied at Nodes B - D

\begin{tabular}{|c|c|c|c|c|c|c|}
\hline Analysis & $\begin{array}{c}\text { Loading } \\
\text { point }\end{array}$ & \multicolumn{5}{|c|}{ Transverse deflection } \\
& & Node A & Node B & Node C & Node D & Node E \\
\cline { 2 - 7 } & Node B & 21.0 & $83.0^{*}$ & 30.5 & 2.5 & -0.7 \\
\hline \multirow{3}{*}{ FE model } & Node C & 2.6 & 31.9 & $44.4^{*}$ & 30.9 & 1.9 \\
\cline { 2 - 7 } & Node D & -0.8 & 2.4 & 30.3 & $84.1^{*}$ & 22.2 \\
\hline \multirow{2}{*}{$\begin{array}{c}\text { Experimental } \\
\text { test result }\end{array}$} & Node B & 15.4 & $85.9^{*}$ & 35.4 & 3.3 & -0.9 \\
\cline { 2 - 7 } & Node C & 2.1 & 32.2 & $47.4^{*}$ & 30.8 & 1.6 \\
\cline { 2 - 7 } & Node D & -0.2 & 2.0 & 30.6 & $84.4^{*}$ & 20.8 \\
\hline \multirow{2}{*}{$\begin{array}{c}\text { FE model / } \\
\text { Experimental } \\
\text { deflection }\end{array}$} & Node B & $\mathbf{1 . 4}$ & $\mathbf{1 . 0 *}$ & $\mathbf{0 . 9}$ & $\mathbf{0 . 8}$ & $\mathbf{0 . 8}$ \\
\cline { 2 - 7 } & Node C & $\mathbf{1 . 2}$ & $\mathbf{1 . 0}$ & $\mathbf{0 . 9}$ & $\mathbf{1 . 0}$ & $\mathbf{1 . 2}$ \\
\cline { 2 - 7 } & Node D & $\mathbf{4 . 0}$ & $\mathbf{1 . 2}$ & $\mathbf{1 . 0}$ & $\mathbf{1 . 0 *}$ & $\mathbf{1 . 1}$ \\
\hline
\end{tabular}

* represents the deflection values corresponding to the same respective loading node

The ratios between the FE model and the experimental deflections at the respective loading Nodes B, C and D are 1.0, 0.9 and 1.0, respectively. This shows that the deflections predicted by the FE analyses at the respective loading Nodes (asterisked in Table 3) show good agreement with the experimental deflections.

The deflections at Nodes B and D when load was applied at these respective nodes were 83.0 $\mathrm{mm}$ and $84.1 \mathrm{~mm}$, respectively, which are very close to each other, as expected. Also, it was expected that the deflection at Node A when the load was applied at Node B should be the same as that of Node E when the load was applied at Node D. The deflections obtained from the FE model at Node A with the load at Node B was $21.0 \mathrm{~mm}$, which is also reasonably close to the deflection at Node E $(22.2 \mathrm{~mm})$ with the load at Node D. Similarly, the deflection at Node C should be the same when load was applied at Nodes B and D. When load was applied at Nodes $B$ and $D$, the deflections predicted by the FE model at Node $C$ were $30.5 \mathrm{~mm}$ and $30.3 \mathrm{~mm}$, respectively, i.e. almost equal values.

In general, when the load was applied at Nodes B and D, it can be seen that the predicted FE deflections are in good agreement with experimental deflections, except for the corresponding deflections at Node A (see Table 3). The ratios between the FE model and the experimental deflection at Node A, when load was applied at Nodes B and D were 1.4 and 4.0 , respectively. The poorer agreement between the deflections at Node A when load was applied at Nodes B and D can be attributed to the fact the FE model of the PVC fence assumed 
that the cut-outs in the PVC posts were in complete contact with the faces/edges of the PVC rails (see Figure $27 \mathrm{~b}$ ), thus allowing a greater redistribution of load to the outer posts of the two-bay PVC fence. However, in practice, there were small clearances between the cut-outs and the faces/edges leading to relative movement (minor slip) at the PVC rail-to-post connections which limited load re-distribution effects across each bay of the two-bay PVC fence (see Figure 27a). Furthermore, the actual difference between the predicted FE model and the average experimental deflection at Node A when load was applied at Node D was only $0.6 \mathrm{~mm}$, even though the percentage difference appears significant.

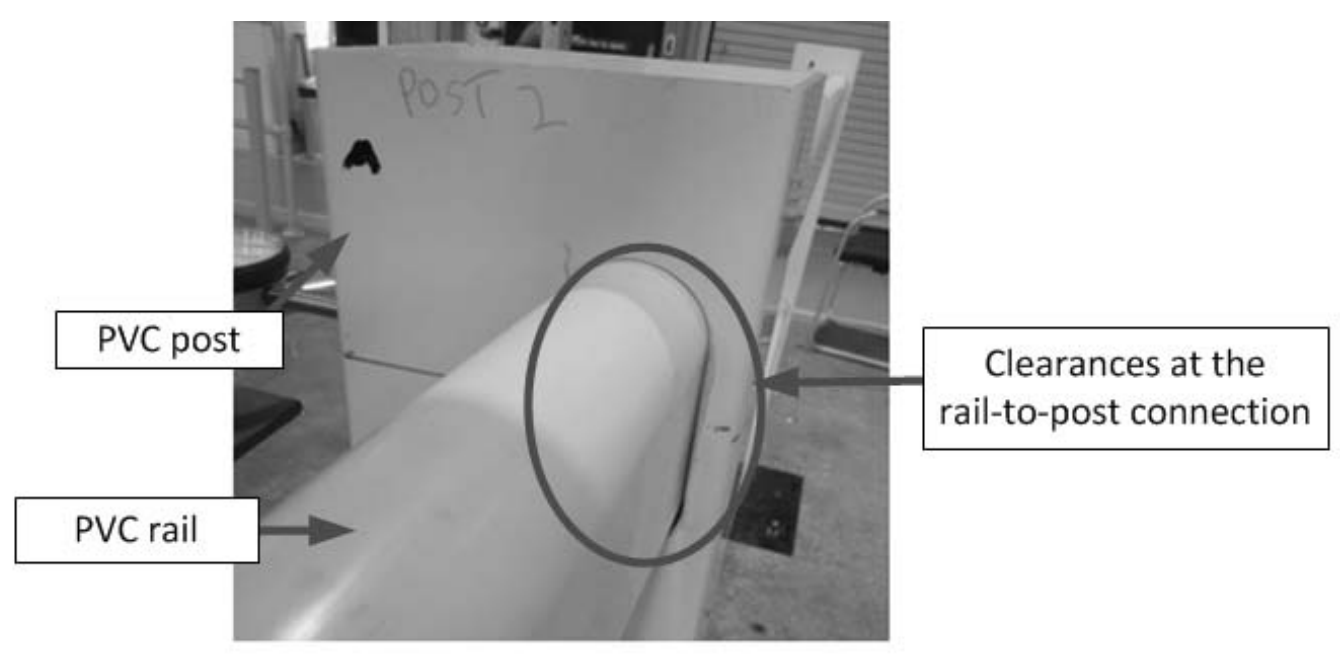

(a)

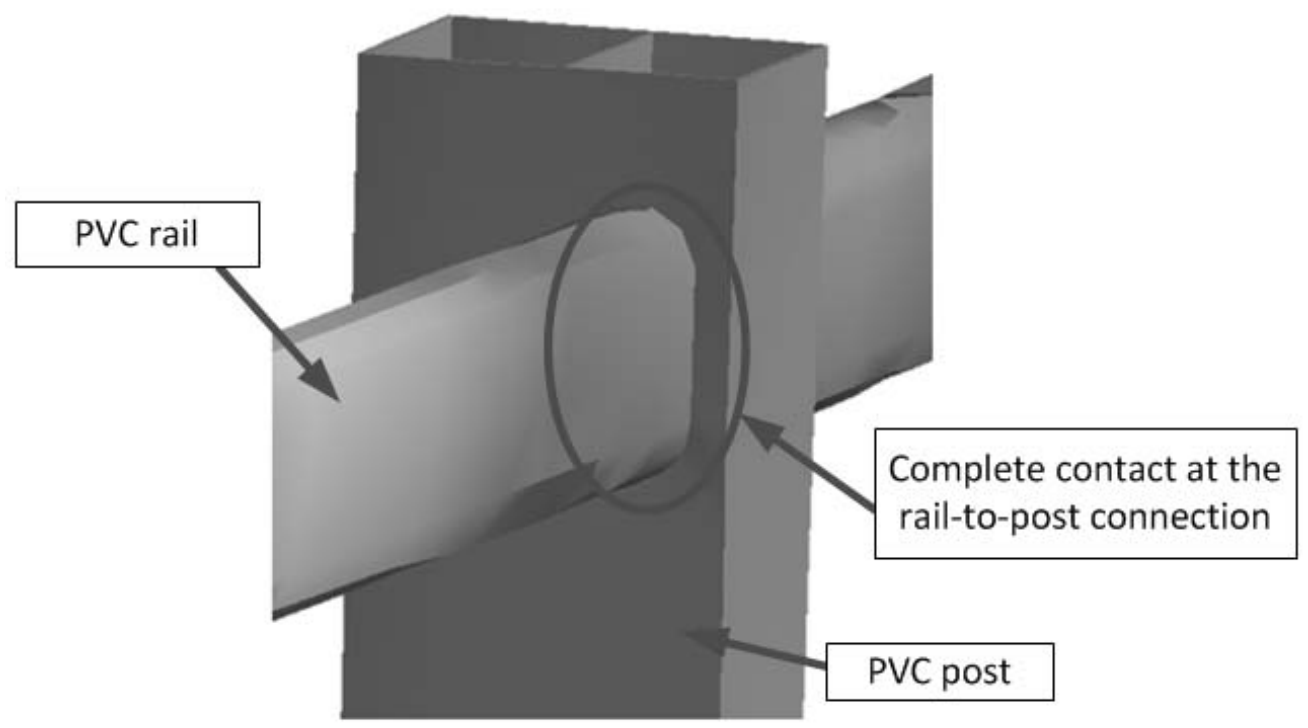

(b)

Figure 27: Images showing the (a) Experimental and (b) FE rail-to-post connections 


\section{Concluding Remarks}

This paper describes the experimental load tests and Finite Element (FE) modelling of twobay PVC post and rail fences which are representative of typical multi-bay fencing systems. Also, descriptions of the PVC posts and rails and their properties have been presented. The experimental load tests and FE analyses were evaluated to determine the load-deformation responses of the two-bay PVC fence. The test setup, instrumentation and analysis techniques have been described, and images of the test setups have also been presented. Results obtained from the experimental tests have been presented, discussed and analysed. Details of the FE analyses carried out have also been presented, and the predicted FE deflections have been compared with the corresponding experimental deflections. Good correlation between the FE analyses and experimental test results has been demonstrated. Hence, isotropic linear elastic FE models using ANSYS are able to predict the load-deformation responses of the fencing structures for reasonably large transverse deflections.

Two sets of load tests were carried out on the PVC post and rail fences, with the main difference being their overall geometry. The overall geometry of the first set of load tests is the same as that typically used for agricultural PVC fencing, which had a post spacing of 2000 $\mathrm{mm}$. However, in the second set of load tests, the spacing between the PVC posts was reduced from $2000 \mathrm{~mm}$ to $1800 \mathrm{~mm}$ to correspond with that of the similar timber fence for which test data was already available. The transverse stiffness of the PVC fence was calculated by dividing the maximum load applied to the centre post by its average transverse deflection. The transverse stiffnesses for the first and second set of tests on the PVC fences were 12.7 $\mathrm{N} / \mathrm{mm}$ and $14 \mathrm{~N} / \mathrm{mm}$, respectively. These results showed that the relative transverse stiffness of the two-bay timber fence was approximately $262 \%$ greater than that of the similar PVC fence. The load test results also showed that a reduction in the distance between the PVC posts of $200 \mathrm{~mm}$ resulted in an approximate $10 \%$ increase in the relative transverse stiffness.

Computationally efficient shell elements (SHELL181) were used to model the PVC posts and rails and the steel base plate with welded steel angles. The six rail-to-post connections were modelled with CONTA174 and TARGE170 elements using ANSYS software. Line loads were applied at the top of the centre post and the mid-bay points of the top rail of the two-bay PVC fence. The ratios of the FE model to the experimental deflections at the loading nodes range 
from 0.9 to 1.0, reflecting good to excellent correlation with the experimental results at the respective loading nodes. When the maximum load of $600 \mathrm{~N}$ was applied at the centre PVC post, the deflections predicted from the FE analysis varied from about $10 \%$ lower to $20 \%$ higher than the experimental deflections. On the other hand, greater differences between the predicted FE and experimental deflections were observed at the top rail-to-post connections of the outer PVC posts when load was applied at the mid-bay of the top rail. This discrepancy has been discussed and is due to limited stiffness continuity effects (across the bays in the experimental tests) due to the presence of small clearances leading to relative movement (slip) between the rails and posts at the cut-outs in the PVC posts and the edges/faces of the PVC rails. In contrast, the FE analysis assumed full interaction at the railto-post connections of the two-bay PVC fence model. The FE analysis also took into account some unique features of the PVC fencing structure namely: (a) the PVC posts and rails were hollow sections with different cross-sectional shapes and the rails passed through only one of the two cells of each post, and were not rigidly connected to the cell walls, (b) the lower region of each PVC post was stiffened by an internal steel angle with frictional contact between the angle legs and the interior cell walls of the post, and finally, (c) the base of each PVC post is not rigidly connected to its steel base plate and separation between the plate and bottom of the PVC post may occur during testing. All of the aforementioned factors were included in the FE modelling and analysis.

In summary, FE analyses have been carried out to complement experimental testing, and has been useful in predicting the load-deformation responses of the two-bay PVC fences. As there have been no FE analyses or experimental load tests on PVC fencing in the open literature, this study adds to the limited knowledge base on the serviceability deformation response of PVC post and rail fences and contributes to the development of potentially useful design guidance. The experimental and FE PVC fencing results also provide useful benchmarks for assessing the structural stiffness of novel composite materials and components for fencing applications.

\section{Acknowledgments}

The authors would like to record their appreciation for financial support from the Centre for Global Eco-Innovation and the Engineering Department of Lancaster University. The Centre 
for Global Eco-Innovation is part-financed by the European Regional Development Fund (Grant no. X02646PR). Furthermore, the authors also wish to thank Mr Mark Salisbury, who assisted with the experimental aspects of this research. 


\section{References}

Agarwal, Sushant, and Rakesh K. Gupta. 2011. "Plastics in Buildings and Construction." In Applied Plastics Engineering Handbook, edited by Myer Kutz, 553-564. Oxford: William Andrew Publishing.

American Chemistry Council. 2008. "The Economic Benefits of Polyvinyl Chloride in the United States and Canada." accessed 17th February. http://www.pvc.org/upload/documents/The Economics of PVC.pdf.

ANSYS Workbench Release 15. User's Guide ANSYS Inc. Canonsburg, PA.

ASTM F964. 2013. Standard Specification for Rigid Poly (Vinyl Chloride) (PVC) Exterior Profiles Used for Fencing and Railing. West Conshohocken, PA: ASTM International.

ASTM F1999. 2006. Standard Practice for Installation of Rigid Poly(Vinyl Chloride) (PVC) Fence Systems. West Conshohocken, PA: ASTM International.

Bakis, C. E., L. C. Bank, VI Brown, E. Cosenza, Jf Davalos, Jj Lesko, A. Machida, Sh Rizkalla, and T. C. Triantafillou. 2002. "Fiber- reinforced polymer composites for constructionstate-of-the- art review." J. Compos. Constr. 6:73-87. doi: 10.1061/(ASCE)10900268(2002)6:2(73).

BS 527-1. 2012. Plastics. Determination of tensile properties. General principles. London: British Standards Institution.

BS 14122-3. 2016. Safety of machinery. Permanent means of access to machinery. Stairs, stepladders and guard-rails London: British Standards Institution.

BS EN 178. 2013. Plastics - Determination of flexural properties London: British Standards Institution.

Callister, W.D., and D.G. Rethwisch. 2008. Fundamentals of Materials Science and Engineering: An Integrated Approach. 3rd ed. New Jersey: Wiley.

Duralock Performance Fencing. 2014. "Installation guides." accessed 15 June. http://www.duralock.com/en/about-us/installation-guides.

European Council of Vinyl Manufacturers. 2014. "How is PVC used?", accessed 7th February. http://www.pvc.org/en/p/how-is-pvc-used.

German, R.L. 1992. Fence Rail Connection. US: Google patents.

Kalpakjian, Serope. 1984. Manufacturing processes for engineering materials. Massachusetts: Addison-Wesley.

Pakala, Purushotham, Venkatesh Kodur, and Mahmoud Dwaikat. 2012. "Critical factors influencing the fire performance of bolted double angle connections." Engineering Structures 42:106-114. doi: 10.1016/j.engstruct.2012.04.011.

Patrick, S.G. 2005. Practical Guide to Polyvinyl Chloride. Shropshire: Rapra Technology Limited.

PlasticsEurope. 2015. "Plastics - The Facts 2015, An Analysis of European Plastics Production, Demand and Waste data." PlasticsEurope Association of Plastics Manufacturers, accessed 4th February. http://www.plasticseurope.org/Document/plastics---thefacts-2015.aspx.

Satasivam, Sindu, and Yu Bai. 2014. "Mechanical performance of bolted modular GFRP composite sandwich structures using standard and blind bolts." Composite Structures 117:59-70. doi: 10.1016/j.compstruct.2014.06.011. 
Sotayo, Adeayo, Sarah Green, and Geoffrey Turvey. 2016. "Experimental and Finite Element (FE) modelling of timber fencing for benchmarking novel composite fencing." Composite Structures 158:44-55. doi: 10.1016/j.compstruct.2016.07.082.

Tsavdaridis, Konstantinos Daniel, and Theodore Papadopoulos. 2016. "A FE parametric study of RWS beam-to- column bolted connections with cellular beams." Journal of Constructional Steel Research 116:92-113. doi: 10.1016/j.jcsr.2015.08.046.

Turvey, Geoffrey. 2015. "Experimental investigation of the load-deformation behaviour of pultruded GFRP modular and custom safety barriers." Composite Structures 133:659666.

Yu, Jie, Lushi Sun, Chuan Ma, Yu Qiao, and Hong Yao. 2016. "Thermal degradation of PVC: A review." Waste management 48:300-314. doi: 10.1016/j.wasman.2015.11.041. 